\title{
Current and past menstrual status is an important determinant of femoral neck geometry in exercising women
}

Rebecca J. Mallinsona, Nancy I. Williams ${ }^{a}$, Jenna C. Gibbs ${ }^{a, b}$, Karsten Koehlera,c, Heather C.M. Allawaya, Emily Southmayda, and Mary Jane De Souzaa

a Pennsylvania State University, Department of Kinesiology, Noll Laboratory, University Park, PA 16802

b University of Waterloo, Department of Kinesiology, 200 University Ave W, Waterloo, ON, N2L 3G1, Canada.

c University of Nebraska, Department of Nutrition and Health Sciences, Lincoln, NE 68583

Email Addresses:

Rebecca J. Mallinson (mallinsonrj@gmail.com); Nancy I Williams (niw1@psu.edu); Jenna C. Gibbs (jenna.gibbs@uwaterloo.ca); Karsten Koehler (kkoehler3@unl.edu); Heather C.M. Allaway (hca111@psu.edu); Emily Southmayd (eas5377@psu.edu); Mary Jane De Souza (mjd34@psu.edu)

\section{Corresponding Author:}

Rebecca J. Mallinson, Ph.D.

Women's Health and Exercise Laboratory, Noll Laboratory

Pennsylvania State University, University Park, PA 16802

Phone: 607-437-6682

E-mail: mallinsonrj@gmail.com 


\section{Abstract}

Menstrual status, both past and current, has been established as an important determinant of bone mineral density (BMD) in young exercising women. However, little is known regarding the association between the cumulative effect of menstrual status and indices of bone health beyond BMD, such as bone geometry and estimated bone strength. Purpose: To explore the association between cumulative menstrual status and indices of bone health assessed using dual-energy $x$-ray absorptiometry (DXA), including femoral neck geometry and strength and areal BMD (aBMD), in exercising women. Methods: 101 exercising women (22.0 \pm 0.4 years, BMI $21.0 \pm 0.2 \mathrm{~kg} / \mathrm{m}^{2}, 520 \pm 40$ minutes/week of self-reported exercise) participated in this cross-sectional study. Women were divided into three groups as follows based on their self-reported current and past menstrual status: 1) current and past regular menstrual cycles (C+P-R) (n=23), 2) current and past irregular menstrual cycles $(C+P-I R)(n=56), 3)$ and current or past irregular cycles (C/P-RIR) $(n=22)$. Current menstrual status was confirmed using daily urinary metabolites of reproductive hormones. DXA was used to assess estimates of femoral neck geometry and strength from hip strength analysis (HSA), aBMD, and body composition. Cross-sectional moment of inertia (CSMI), cross-sectional area (CSA), strength index (SI), diameter, and section modulus (Z) were calculated at the femoral neck. Low CSMI, CSA, SI, diameter, and Z were operationally defined as values below the median. Areal BMD $\left(\mathrm{g} / \mathrm{cm}^{2}\right)$ and Z-scores were determined at the lumbar spine, femoral neck, and total hip. Low BMD was defined as a Z-score <-1.0. Chi-square tests and multivariable logistic regression were performed to compare the prevalence and determine the odds, respectively, of low bone geometry, strength, and aBMD among groups. Results: Cumulative menstrual status was identified as a significant predictor of low femoral neck CSMI $(p=0.005), \operatorname{CSA}(p \leq 0.024)$, and diameter $(p=0.042)$ after controlling for confounding variables. $C+P-I R$ or $C / P-R I R$ were four to eight times more likely to exhibit low femoral neck CSMI or CSA when compared with C+P-R. Lumbar spine aBMD and Z-score were lower in C+P-IR when compared with $C+P-R(p \leq 0.003)$. A significant association between menstrual group and low aBMD was observed at the 
lumbar spine $(p=0.006)$ but not at the femoral neck or total hip $(p>0.05)$. However, after controlling for confounding variables, cumulative menstrual status was not a significant predictor of low aBMD.

Conclusion: In exercising women, the cumulative effect of current and past menstrual irregularity appears to be an important predictor of lower estimates of femoral neck geometry, as observed by smaller CSMI and CSA, which may serve as an another means, beyond BMD, by which menstrual irregularity compromises bone strength. As such, evaluation of both current and past menstrual status is recommended to determine potential risk for relatively small bone geometry at the femoral neck.

Keywords: Female Athlete Triad, Functional Hypothalamic Amenorrhea, Low Bone Mineral Density, Bone Geometry, Hip Strength Analysis 


\section{Introduction}

Menstrual irregularity among exercising girls and women is associated with lower bone mineral density (BMD) [1-4], compromised bone geometry and microarchitecture [5-7], and a higher risk of bone stress injuries [8-10] when compared with healthy eumenorrheic counterparts or sedentary girls and women. Among exercising women and girls, the prevalence of menstrual disturbances has been reported to be as high as $60 \%$ [11], and the co-existence of menstrual irregularity and compromised BMD has been repeatedly observed [4, 5, 12-15]. Functional hypothalamic amenorrhea, defined as the absence of menses for greater than 90 days (secondary amenorrhea) [16] or the failure to attain menarche by age 15 (primary amenorrhea) [17] which cannot be explained by other underlying pathology [17], and oligomenorrhea, defined as irregular and inconsistent menses at intervals of 36 to 90 days [16], are the most severe presentations of menstrual cycle disturbances and are linked to poor skeletal health $[3,5,8]$. Low BMD in female athletes is defined as a Z-score between -1.0 and -2.0 in combination with a history of inadequate nutrition, hypoestrogenism, and stress fractures; whereas, the term "osteoporosis" is reserved for a BMD Zscore $\leq-2.0$ with secondary risk factors for fracture [18]. For the purpose of this paper, low BMD will be defined as a Z-score <-1.0.

Physiologically, chronic menstrual irregularity is linked to poor skeletal health due to the underlying influence of estrogen and metabolic hormones on bone resorption and formation. Estrogen is a potent inhibitor of osteoclast action [19]; therefore, the low estrogen concentrations characteristic of amenorrhea result in increased bone resorption [20]. Frequently among female athletes, an energy deficiency that alters circulating concentrations of metabolic hormones is at the root of the menstrual irregularity, and these metabolic adaptations suppress bone formation [20, 21]. Consequently, an uncoupling of bone resorption and formation is typically occurring in the presence of menstrual irregularity; thereby creating an unfavorable environment for skeletal health. 
To date, research in exercising women has focused primarily on the impact of current menstrual status (i.e. menstrual status within the past year) on indices of bone health. Substantial evidence demonstrates that female athletes presenting with amenorrhea have significantly lower BMD at the lumbar spine in comparison to their eumenorrheic counterparts $[2-5,12-15,22]$. Less consistently, lower BMD at the femoral neck and/or total hip has also been observed $[4,5,14,15]$. In addition, investigators have recently demonstrated that bone geometry and microarchitecture may also be compromised in amenorrheic athletes [5-7], providing further evidence for compromised bone strength in these athletes. However, results for BMD and bone geometry at weight-bearing sites, such as the femoral neck and total hip, have not been consistently reported. Notably, our laboratory has not observed significant differences in BMD and bone geometry at the femoral neck and total hip between amenorrheic and eumenorrheic athletes [12, 13].

It is equally important to understand the role of past menstrual status on bone health in young exercising women because the majority of bone mineral accrual in women occurs in adolescence [23], and, notably, in girls, the greatest gains in bone mass occur between the ages of 11 and 14 years [23]. Peak bone mass is typically attained during the latter years of the second decade or early years of the third decade [24]. For this reason, oligo/amenorrhea during adolescence is hypothesized to contribute to more substantial decrements in bone health when compared with oligo/amenorrhea in adulthood [25], and longterm amenorrhea may confer the most harmful effects on BMD [3]. Chronically low BMD due to failure to accrue optimal bone mass during adolescence or substantial bone loss during early adulthood may increase the long-term and life-long risk of osteoporotic fractures [26].

Several contemporary studies $[7,8,27-30]$ and classic studies [31, 32] have explored the impact of past menstrual status, i.e., menstrual history, on bone health. Investigators of these studies reported that, in female athletes, self-reported history of irregular menstrual cycles since menarche was associated with low BMD (Z-score $\leq-1)$ [29] or with lower BMD compared with a history of regular menses [7, 28, 31, 32] and with history of stress fracture [8]; however, geometric measures of the femoral neck were similar between 
those with a history of regular vs. irregular menses since menarche [7]. Results from Ducher et al. [27], who used peripheral quantitative computed tomography ( $\mathrm{PQCT}$ ) to assess bone health, revealed that retired gymnasts with a history of amenorrhea had significantly lower trabecular volumetric BMD and estimated bone strength but greater total bone area at the distal radius when compared with retired gymnasts with a history of regular menses.

The cumulative effect of current and past menstrual irregularity may be a stronger predictor of diminished BMD than current menstrual irregularity alone [3]; however, to our knowledge, there is a limited number of studies designed to assess bone health, namely $\mathrm{BMD}$, in women grouped according to cumulative menstrual status, i.e. categorized by considering both past and current menstrual status [3]. Using dual-photon absorptiometry (DPA), Drinkwater et al. [3] demonstrated that female athletes with consistent severe menstrual disturbances currently and in the past had 17\% lower lumbar spine BMD when compared with women who were previously, and currently, regularly-menstruating. In addition to the "classical" measure of BMD, bone geometry has been emerging as an important focal area when assessing overall bone health and fracture risk; however, to our knowledge, the association between cumulative menstrual status and bone geometry has not been reported in young exercising women when grouped according to past and current menstrual status as done in the aforementioned classic study [3] . Bone size and distribution of the bone mass greatly influence the strength of the bone $[33,34]$. In fact, doubling the radius of the bone will increase the strength of the bone sixteen-fold [34] and distributing the bone mass farther away from the central axis will further increase the strength of the bone [34]. Algorithms have been created to estimate the geometrical measures of cross-sectional area (CSA), cross-sectional moment of inertia (CSMI), and diameter at the femoral neck using DXA [35], and from these measures, a strength index (SI) that indicates the ability of the femoral neck to resist fracture during a fall has been developed [35]. In addition, a measure of bending strength, known as section modulus (Z), can be calculated [36, 37]. Due to the known contribution of bone geometry to overall bone strength and fracture risk [33], exploration 
of the association between cumulative menstrual status and estimates of bone geometry and strength at the femoral neck would be informative.

Comprehensive examination of estimated bone geometry and strength in exercising women categorized by cumulative menstrual status may offer valuable insight on risk assessment and targets for interventions to improve bone health. The assessment of cumulative menstrual status may represent a practical indicator of risk for compromised bone geometry and low BMD that physicians and other healthcare providers who manage and treat female athletes can evaluate in a clinical or field setting. To this end, the purpose of this study was to evaluate the association between cumulative menstrual status and indices of bone health (bone geometry, estimated bone strength, and BMD) assessed using DXA in premenopausal exercising women. We hypothesize that estimated bone geometry and strength at the weight-bearing femoral neck will be similar among exercising women grouped according to cumulative menstrual status; therefore, there will not be an association between cumulative menstrual status and lower estimates of bone geometry and strength at the femoral neck. We further hypothesize that exercising women with both current and past menstrual irregularity will demonstrate significantly lower BMD in comparison to exercising women with current and past regular menses and exercising women with current menstrual irregularity and past regular menses or current regular menses and past irregular menses. In addition, we hypothesize that cumulative menstrual status will be a significant predictor of low BMD.

\section{Materials and Methods}

\subsection{Study Design}

This cross-sectional investigation combines 1) baseline data from a randomized controlled trial designed to assess the effects of a 12-month intervention of increased energy intake on indices of bone health and menstrual status in exercising women with menstrual disturbances compared to eumenorrheic exercising women ( $n=96)$, and 2) data from an observational study assessing energy status and indices of bone strength in exercising and sedentary young women $(n=5)$. The studies were approved by the 
appropriate Institutional Review Boards of the University of Toronto and the Pennsylvania State University, and all participants signed an approved informed consent document.

\subsection{Participants}

Women were eligible for this study if they met the following criteria: (1) between 18 and 35 years of age; (2) good health status; (3) body mass index (BMI) between 16 and $25 \mathrm{~kg} / \mathrm{m}^{2}$; (4) participated in at least two hours per week of purposeful exercise; (5) non-smoker; (6) no hormonal therapy for the past six months; (7) not pregnant or lactating; (8) no medication use that would alter metabolism or skeletal health; and (9) no other contraindications that would prevent study participation.

\subsection{Menstrual Group Categorization}

Participants were retrospectively grouped according to current and past menstrual status, also referred to as cumulative menstrual status, to yield three study groups as follows: current and past regular menstrual cycles ( $C+P-R)$, current and past irregular menstrual cycles $(C+P-I R)$, and current or past irregular cycles (C/P-RIR). For this third group (C/P-RIR), regular cycles characterized the time period that was not characterized by irregular menstrual cycles, i.e., women were placed in this group if they were 1) eumenorrheic at the time of study participation but had a history of oligo/amenorrhea or 2) oligo/amenorrheic at the time of study participation but had a history of eumenorrheic cycles. To create these menstrual groups, each woman was placed in a group for current menstrual status and a group for past menstrual status prior to creating the final cumulative menstrual status grouping as described below.

\subsubsection{Current Menstrual Status Categorization.}

Current menstrual status was determined in all participants and defined as the number of selfreported menstrual cycles in the past 12 months. Participants met criteria for current menstrual irregularity if they were amenorrheic (no menses for 3 consecutive months $\mathrm{OR}<5$ cycles in the past 12 months) or oligomenorrheic (5-9 cycles in the past 12 months AND menses within the past 3 months). Women met criteria for regular menstrual cycles if they reported at least 10 cycles in the past 12 months AND menses 
within the past 3 months. Duration of amenorrhea was estimated from self-reported last menstrual period or number of menses within the past 3-12 months.

Self-reported current menstrual status was then confirmed prospectively by classifying menstrual cycles by length of the intermenstrual interval, the presence of menses, and characteristic reproductive hormone profiles [16]. These determinations were made from the measurement of daily urinary ovarian steroid metabolites, estrone-1-glucuronide (E1G) and pregnanediol glucuronide (PdG), as previously described $[16,38]$. E1G and PdG were measured in each urine sample using microtiter plate competitive enzyme immunoassays and a polyclonal capture antibody supplied by Coralie Munro University of California (Davis, CA) as previously reported $[12,16]$. Urinary concentrations of E1G and PdG were corrected for specific gravity to account for hydration status. Participants who were currently eumenorrheic collected daily urine samples for one complete menstrual cycle; whereas, women who were currently amenorrheic collected daily urine samples for at least one 28-day monitoring period, and women who were currently oligomenorrheic collected daily urine samples for at least 28 but no more than 90 days. Amenorrheic monitoring periods typically demonstrated chronically suppressed E1G and PdG profiles without the occurrence of menses. Cycles were classified as oligomenorrheic if the cycle length was between 36-90 days. Eumenorrheic cycles were required to have an intermenstrual interval of 24-35 days. Women who presented with a normal ovulatory cycle, luteal phase defect (short and/or in adequate luteal phase) or anovulatory cycle were included in the analysis.

Based on the definitions described above, women were categorized as exhibiting a current menstrual status that was irregular (amenorrhea or oligomenorrhea in the past 12 months) or regular. This "current menstrual status" group contributed to the final groups used for statistical analysis.

\subsubsection{Past Menstrual Status Categorization.}

Self-reported past menstrual status was determined using a menstrual history questionnaire. An affirmative answer to the question "Have you, in the past, gone for any length of time without menstruating 
regularly?" indicated past menstrual irregularity. Those who reported past menstrual irregularity were asked to provide information about the duration of the episode(s), the age at which the episode(s) occurred, and the circumstances surrounding the episode(s). Women who had a history of primary amenorrhea (menarche that occurred on or after the age of 15 [17]) were also considered to have past menstrual irregularity even if all cycles after the onset of menarche were reported to be regular. As such, women were categorized as exhibiting a past menstrual status that was either irregular or regular. These "past menstrual status" groups contributed to the final groups used for analysis. Physiological or drug-induced periods of amenorrhea such as pregnancy, lactation, or contraceptive use were not included in this grouping.

\subsubsection{Final Menstrual Status Categorization}

The current and past menstrual status categories were evaluated in combination to create the three aforementioned groups used for analysis. Women who had regular menstrual cycles currently and in the past were placed in the C+P-R group. Women who had irregular menstrual cycles currently and in the past were placed in the C+P-IR, and women who had irregular menstrual cycles currently or in the past (and were therefore categorized as having regular menstrual cycles for the time period not represented by irregular menstrual cycles) were placed in the C/P-RIR group.

\subsubsection{Other Menstrual Status Descriptives}

Independent of the primary menstrual groups described above, subjects were also described as achieving menarche at a normal age ( $<15$ years) or a late age ( $\geq 15$ years) [17]. Gynecological age was calculated by subtracting age of menarche from current age.

\subsection{Sport Categorization}

Based on their primary sport participation, each woman was grouped into sport categories to serve as predictors of low BMD and femoral neck geometry. The categories were based on 1) whether the sport emphasized leanness and 2) the mechanical impact of the sport. Classification into leanness sport categories was conducted according to classification systems published by Sundgot-Borgen and Larsen 
[39] and Torstveit and Sundgot-Borgen [40]. Leanness sports included endurance, aesthetic, and antigravitation activities, and non-leanness sports included technical, ball game, and power sports. Due to the primarily recreational nature of the exercise of our participants, this classification system was slightly modified. Women participating in martial arts classes or recreational weight-lifting were considered nonleanness rather than leanness sports because they did not have to meet a certain weight requirement in order to participate.

For the mechanical impact category, a classification system by Torstveit and Sungot-Borgen [41] and based on the method by Groothausen and Siemer [42] was used. The primary sport of each woman was categorized as "low impact," "moderate impact," or "high impact." Low impact sports included nonweight bearing sports or sports that primarily involved standing [41]. Moderate impact sports included weight-bearing sports, those with moderate mechanical loading, and sports involving sprinting and turning movements [41]. Lastly, high impact sports were defined as weight-bearing sports with high mechanical loading and primarily included sports with jumping and/or rapid movements [41].

\subsection{Anthropometric, Body Composition, HSA, and BMD Data}

Body weight was measured on a digital scale, and height was measured using a stadiometer. Body composition (percent body fat, fat mass, and lean body mass) and areal BMD (aBMD) at the lumbar spine and dual femur $(\mathrm{n}=92)$ or left femur $(\mathrm{n}=9)$ were obtained by DXA. Lean mass index $(\mathrm{LMI})$ was calculated as lean body mass divided by height squared $\left(\mathrm{kg} / \mathrm{m}^{2}\right)$. Femoral neck CSMI, CSA, SI, and diameter were estimated from dual femur scans (mean of right and left hip) by hip strength analysis (HSA) as developed by Yoshikawa et al. [35] and as previously reported [12]. Section modulus (Z) was calculated as CSMI/y [36] where $y$ represents the distance from the center of mass to the superior neck margin for the section of minimum CSMI [35]. The majority of women were scanned on either a GE Lunar Prodigy ( $n=35$, enCORE 2002 software version 6.50.069) or a GE Lunar iDXA ( $n=58$, enCORE 2008 software version 12.10.113). The remaining women $(n=9)$ were scanned on a Hologic QDR4500W DXA scanner (Hologic Inc., Bedford, 
MA); however, an additional dual femur scan was performed on the Lunar iDXA for three of these women to obtain estimates of femoral neck geometry since HSA was only available for scans performed on the GE devices. Because the other 6 women scanned on the Hologic system were not available to complete a scan on the iDXA, HSA data is missing for these women and explains the slightly larger sample size for BMD parameters ( $n=101)$ versus bone geometry and strength parameters $(n=95)$.

Consistent with the International Society for Clinical Densitometry guidelines, a cross calibration study was performed to remove systematic bias between the systems, and all systems were calibrated to the iDXA. For the cross calibration study between the Lunar Prodigy and Lunar iDXA, 14 participants were scanned in triplicate on both machines and the results for body composition, aBMD, and HSA (mean of right and left femoral neck) for each individual were averaged. The values for body composition, aBMD, and femoral neck geometry were highly correlated $(r>0.85)$. For the cross calibration study between the Hologic QDR4500W and the Lunar iDXA, 32 women were scanned in duplicate on both machines, and the results for each individual were averaged. High correlations ( $r>0.95)$ were observed between the Hologic and iDXA values for body composition and aBMD as previously reported [12]. Equations were derived using simple linear regression to remove biases. Absolute aBMD and body composition values obtained from both the Lunar Prodigy and the Hologic QDR-4500W were calibrated to the Lunar iDXA; however, the Z-scores obtained from each software system were used for analyses. With a few published exceptions [43], the Lunar software used appropriate age, sex, weight, and ethnicity reference values to calculate the Z-scores; whereas, the Hologic software used age, sex, and ethnicity reference values. All HSA measurements were obtained using the same software (enCORE 2008 software version 12.10.113), and Z was calculated after appropriate conversion of Prodigy HSA data to iDXA values. According to the 2007 ACSM Position Stand on the Female Athlete Triad [18], low BMD was defined as a Z-score <-1.0; whereas normal BMD was a Z-score $\geq-1.0$. GE Lunar software does not contain reference data for the femoral neck or total hip for women less than 20 years of age; therefore, for these women ( $n=25), Z$-scores at these 
two sites were calculated based on age 20 norms [44]. Because no reference values are available for HSA data, low and high CSMI, CSA, SI, neck diameter, and Z were operationally defined as values below and above the median, respectively. As such, low and high CSMI were defined as CSMI $<9,619 \mathrm{~mm}^{4}$ and $\geq 9,619 \mathrm{~mm}^{4}$, respectively; low and high CSA were defined as CSA $<155 \mathrm{~mm}^{2}$ and $\geq 155 \mathrm{~mm}^{2}$, respectively; low and high SI were defined as $\mathrm{SI}<1.749$ and $\geq 1.749$, respectively; low and high neck diameter were defined as diameter $<30.5 \mathrm{~mm}$ and $\geq 30.5 \mathrm{~mm}$, respectively; and low and high $Z$ were defined as $Z<623.4 \mathrm{~mm}^{3}$ and $Z \geq 623.4 \mathrm{~mm}^{3}$, respectively.

\subsection{Statistical Analysis}

All data sets were tested for non-normality, homogeneity of variance, and outliers before statistical hypothesis tests were performed. For variables that were normally distributed and demonstrated homogeneity of variance, one-way analyses of variance (ANOVA) was used to determine group differences in descriptive characteristics and bone health variables. When group differences were observed, Hochberg's GT2 post-hoc test, chosen due to the unequal group sizes [45], was conducted to determine group differences. For variables that displayed non-normal distribution and/or non-homogeneity of variance, non-parametric Kruskal Wallis tests were performed to determine group differences. When group differences were observed, post-hoc analyses using Kruskal Wallis pairwise comparisons, adjusted for multiple comparisons, were conducted. Chi-square tests were performed to compare the prevalence of low CSMI, CSA, aSI, neck diameter, and Z, and low BMD at the lumbar spine, femoral neck, and total hip among groups. Pearson chi-square exact significance values were used for all analyses in which the expected cell count of all cells was greater than 5 . For analyses with an expected cell count less than 5 , the Fisher exact test was used. Binary logistic regression was used to determine whether cumulative menstrual status and potential confounders which have previously been demonstrated to influence bone geometry or BMD (age of menarche, body mass and height, BMI, lean body mass and LMI, leanness sport participation, and sport impact type) [1, 12, 46-49], were significant predictors of low CSMI, CSA, SI, neck 
diameter, and $Z$, and low BMD. The Box-Tidwell test was performed to test the assumption of linearity, which was violated in the hip BMD and Z multivariable regression models. Crude odds ratios were calculated for cumulative menstrual status and aforementioned possible confounders to determine the association between exposure to these variables and the outcome of low bone geometry and strength and low BMD. To determine adjusted odds ratios for the association of cumulative menstrual status with low bone geometry and strength and low BMD when adjusting for other potential confounders, variables observed to be independent predictors $(p<0.05)$ of low bone geometry or low BMD were entered into a multivariable logistic regression model. Data were expressed as mean $\pm \mathrm{SEM}$, and $p<0.05$ was considered statistically significant. Data were analyzed using SPSS for Windows (version 19.0, Chicago, IL) statistical software package (ANOVA, Kruskal Wallis, Chi-square, and logistic regression) and R statistical software (version 3.2.0) (Fisher Exact Test).

\section{Results}

\subsection{Participant Characteristics.}

After retrospective categorization of current and past menstrual status, 101 women were eligible for inclusion, including $23 \mathrm{C}+\mathrm{P}-\mathrm{R}, 22 \mathrm{C} / \mathrm{P}-\mathrm{RIR}$, and $56 \mathrm{C}+\mathrm{P}-\mathrm{IR}$ women. Six of these women did not have HSA measurements, as explained above; therefore, 95 women were eligible for inclusion for all bone geometry and strength analyses (23 C+P-R, $21 \mathrm{C} / \mathrm{P}-\mathrm{RIR}$, and $51 \mathrm{C}+\mathrm{P}-\mathrm{IR})$. Descriptive characteristics of the groups are presented in Tables 1A and 1B. The groups did not differ significantly in height, body mass, and body mass index (BMI) ( $p>0.05)$; however, $C+P-I R$ women were younger than $C+P-R$ women $(p \leq 0.023)$. Percent body fat, fat mass, lean body mass, and LMI were similar among the groups ( $p>0.05)$, and the groups participated in a similar volume of weekly physical activity. C+P-IR women had a later age of menarche compared with $C+P-R$ women $(p \leq 0.011)$, which contributed to $C+P-I R$ women demonstrating a younger gynecological age compared with C+P-R women $(p \leq 0.001)$ and C/P-RIR women $(p=0.042$; BMD sample only). 
The following description of reproductive characteristics pertains to the entire sample $(n=101)$. Among women who presented with current eumenorrhea, the majority of observed cycles were ovulatory $(70 \%)$ and a small percentage of menstrual cycles had a luteal phase defect $(25 \%)$ or were anovulatory (5\%). For those women who presented with current amenorrhea, the duration of amenorrhea averaged $333.8 \pm 54.7$ days for the $C+P-I R$ group $(n=37)$ and $239.0 \pm 26.0$ days for the $C / P-R I R$ group $(n=5)$ by the end of the observation period. For those women who reported a history of irregular menstrual cycles (amenorrhea or oligomenorrhea) after menarche, the average length of time that these women experienced irregular menstrual cycles was $15.1 \pm 2.1$ months for the $C+P-I R$ group $(n=50)$ and $10.0 \pm 3.4$ months for the C/P-RIR group $(n=13)$. Not included in the average were four women who provided no estimate for the length of time with irregular menstrual cycles and three women who reported always being irregular since menarche. For women who had been amenorrheic for many years, the estimated duration of menstrual irregularity was similar for past and current estimates. The mean age of experiencing irregular menstrual cycles or the commencement of irregular menstrual cycles in the past (after menarche) was $17.4 \pm 0.5$ years for the $C+P-I R$ group $(n=52)$ and $17.3 \pm 0.9$ years for the C/P-RIR group $(n=13)$. Twenty women (17 C+P-IR and $3 \mathrm{C} / \mathrm{P}-\mathrm{RIR}$ ) had a history of primary amenorrhea, and the mean age of menarche among these women was $15.7 \pm 0.2$ years. Twenty percent of the women (20/101) experienced late age of menarche, which corresponded to 17 women in the C+P-IR group (30\%), 3 women in the C/P-RIR group (14\%), and no women in the C+P-R group. A history of oral contraceptive $(\mathrm{OC})$ use was reported by $44.6 \%$ of women in the C+P-IR group, $50.0 \%$ of women in the C/P-RIR group, and $39.1 \%$ of women in the C+P-R group. The age of $\mathrm{OC}$ use ranged from 15-32 years.

\subsection{Sport Type.}

Seventy-nine percent of the women (80/101) were participating primarily in leanness sports, and the remaining women $(21 \%, 21 / 101)$ were participating in non-leanness sports (Table 2A). Of the women 
participating in leanness sports, $56 \%$ were in the C+P-IR group, $20 \%$ were in the C/P-RIR group, and $24 \%$ were in the $\mathrm{C}+\mathrm{P}-\mathrm{R}$ group.

Moderate impact sports represented the primary loading modality overall and within each group (Table 2B). Seventy-two percent (73/101) participated in a moderate impact sport as their primary activity. Only 12\% (12/101) participated in low impact sports, and 16\% (16/101) participated in high impact sports. Within the C+P-IR group, 9\% (5/56), 75\% (42/56), and 16\% (9/56) participated in low impact, moderate impact, and high impact sports, respectively. Within the C/P-RIR group, 14\% (3/22), 64\% (14/22), and 23\% (5/22) primarily engaged in low, moderate, and high impact sports, respectively. Likewise, the C+P-R group displayed a similar pattern with 17\% (4/23), 74\% (17/23), and 9\% (2/23) participating in low impact, moderate impact, and high impact sports, respectively.

\subsection{Bone Geometry and Bone Mineral Density.}

Tables $3 \mathrm{~A}$ and $3 \mathrm{~B}$ describe femoral neck geometry and $\mathrm{aBMD}$ of the groups. Estimates of femoral neck geometry and strength did not differ significantly among the groups ( $p>0.05)$. Larger neck diameter was observed in the $C / P-R I R$ group compared with the $C+P-I R$ women $(p=0.06)$ and the $C+P-R$ women $(p=0.097)$ but did not reach statistical significance after post hoc analyses. No differences were observed among the groups for absolute aBMD nor Z-scores at the femoral neck or total hip ( $p>0.05)$. However, lumbar spine aBMD $(p=0.003)$ and $Z$-score $(p=0.002)$ were significantly lower in the $C+P-I R$ group when compared with the C+P-R group. A total of 21 women (21\%) reported a history of stress fracture. Of these women, $62 \%$ were in the C+P-IR group, $14 \%$ were in the C/P-RIR group, and $24 \%$ were in the C+P-R group.

\subsection{Association between cumulative menstrual status and DXA-derived bone geometry and BMD.}

Figure 1 provides the percentage of women in each menstrual group who had low femoral neck geometry or strength. Menstrual group was associated with neck diameter $\left(X^{2}=10.018, p=0.007\right)$; however, no significant associations were observed between menstrual group and CSMI $\left(X^{2}=3.856, p=0.146\right)$, CSA 
$\left(X^{2}=4.520, p=0.111\right), S I\left(X^{2}=1.317, p=0.518\right)$, or $Z\left(X^{2}=2.466, p=0.310\right)$. Figure 2 demonstrates the percentage of women in each menstrual group who had low BMD at the lumbar spine, femoral neck, and total hip. There was a significant association between menstrual group and the presence of low BMD at the lumbar spine $\left(X^{2}=10.252, p=0.006\right)$ but not at the femoral neck $(p=0.189)$ or total hip $(p=1.000)$.

Independent predictors of low femoral neck estimated geometry and strength are displayed in

Table 4. Current and past menstrual status was a significant predictor of low femoral neck CSA and diameter. Body mass, height, and lean body mass were significant predictors of all HSA parameters, except SI. Further, BMI and LMI were also significant predictors of low femoral neck CSA and Z. Crude odds ratios for independent predictors of low femoral neck estimated geometry and strength are also presented in Table 4. Women in the C+P-IR group demonstrated 3.0 times greater odds of low femoral neck CSA when compared with the C+P-R group (Wald=4.3, $p=0.039$ ). Interestingly, both the C+P-IR group and the C+P-R group had approximately six times greater odds of low neck diameter compared with the C/P-RIR group (Wald $\geq 6.0, p \leq 0.014$ ). A lower body mass, height, and lean body mass by one unit contributed to an increase in the odds of low femoral neck CSMI, CSA, diameter, and Z by 1.1 to 1.3 times (Wald $\geq 6.8, p \leq 0.009$ ), with the greatest increase in odds being observed with a decrease in lean body mass. Further, a lower BMI and LMI by one unit contributed to an increase in the odds of low femoral neck CSA and $Z$ by 1.3 times, on average (Wald $\geq 4.3, p \leq 0.038$ ).

Independent predictors of low BMD at the lumbar spine, femoral neck, and total hip are displayed in Table 5. Current and past menstrual status, age of menarche, body mass and BMI were significant independent predictors of low BMD at the lumbar spine. Height, lean body mass, and LMI were significant independent predictors of low BMD at the femoral neck. However, of the variables that were assessed, none significantly predicted low BMD at the total hip. Crude odds ratios for independent predictors of low BMD are also presented in Table 5. The odds of women in the C+P-IR group having low BMD at the lumbar spine were 6.8 times greater when compared with women in the C+P-R group (Wald=5.9, $p=0.015$ ). 
The odds of C+P-IR women having low BMD at the lumbar spine were 4.1 times greater when compared with the C/P-RIR group (Wald=4.3, $\mathrm{p}=0.038$ ), and the $\mathrm{C} / \mathrm{P}-\mathrm{RIR}$ group had 1.7 times greater odds of low $B M D$ at the lumbar spine than the $C+P-R$ group (Wald $=0.3, p=0.601$ ). An increase in the age of menarche by one year resulted in a $42 \%$ increase in the odds of having low BMD at the lumbar spine (Wald=5.7, $\mathrm{p}=0.017)$. A lower body mass $(\mathrm{kg})$ and $\mathrm{BMI}\left(\mathrm{kg} / \mathrm{m}^{2}\right)$ by one unit contributed to $1.1($ Wald $=8.7, \mathrm{p}=0.003)$ and 1.4 (Wald=7.7, $p=0.005$ ) times greater odds, respectively, of low BMD at the lumbar spine, and a lower height $(\mathrm{cm})$, lean body mass $(\mathrm{kg})$ and LMI $\left(\mathrm{kg} / \mathrm{m}^{2}\right)$ by one unit contributed to $1.1($ Wald $=4.4, \mathrm{p}=0.036), 1.3$ (Wald=8.0, $p=0.005$ ) and 1.8 (Wald=4.0, $p=0.045$ ) times greater odds, respectively, of low BMD at the femoral neck.

Figures 3 and 4 present the multivariable logistic regression model after entrance of cumulative menstrual status and potential confounding variables into the model. Because they were observed to be independent predictors $(p<0.05)$ of low bone geometry or low BMD, four predictor variables were entered into the model for low femoral neck geometry and strength (cumulative menstrual status, body mass, height, LMI) and five predictor variables were entered for low BMD (cumulative menstrual status, age of menarche, body mass, height, LMI). Leanness sport category and sport impact type were not significant independent predictors of low femoral neck geometry or low BMD at any site; therefore, they were not entered into the multivariable logistic regression model. Further, to reduce potential problems with multicollinearity and overfitting the model, BMI and lean body mass were not entered into the multivariable logistic regression model despite being independent significant predictors of low femoral neck geometry and/or BMD. Additionally, we included body mass and height in the model rather than BMI because those variables appeared to be stronger independent predictors of low femoral neck geometry and/or BMD than their counterpart, BMI. LMI was entered into the model rather than lean body mass because LMI demonstrated a lower variance inflation factor (VIF) and therefore less potential problem with multicollinearity than lean body mass. 
Notably, cumulative menstrual status was a significant predictor of low femoral neck CSMI, CSA, and neck diameter after controlling for body mass, height, and LMI (Figure 3). In the multivariable regression model, the odds of C+P-IR women having smaller femoral neck CSMI and CSA were 8.0 times (Wald=7.9, $p=0.005$ ) and 4.5 times (Wald=6.2, $p=0.013$ ) greater, respectively, when compared with the C+P-R group; the odds of C/P-RIR women having smaller femoral neck CSA were 5.0 times greater (Wald=5.1, $p=0.024$ ) when compared with the $C+P-R$ group. On the other hand, the $C+P-R$ group and the C+P-IR group demonstrated 4.8 times (Wald=4.1, $\mathrm{p}=0.042)$ and 8.8 times $($ Wald $=8.9, p=0.003)$ greater odds, respectively, of low neck diameter compared with the C/P-RIR group after controlling for height, weight, and LMI. Body mass was not a significant predictor of low vs. high femoral neck geometry (Wald $\leq 2.1, p \geq 0.148$ ) after controlling for cumulative menstrual status, height, and LMl; however, height remained a significant predictor of low vs. high femoral neck CSMI, neck diameter, and Z after controlling for cumulative menstrual status, body mass, and LMI (Wald $\geq 4.9, p \leq 0.026$ ). LMI was no longer a significant predictor of CSA and $Z$ but became a significant predictor of CSMI (Wald=4.0, $p=0.047$ ), demonstrating that odds of low CSMI increased 1.8 times when LMl was lower by one unit.

When controlling for age of menarche, body mass, height, and LMI, cumulative menstrual status was no longer a significant predictor of low BMD at the lumbar spine (Wald $=3.7, p=0.055 C+P-I R$ vs. $C+P-$ $\mathrm{R} ;$ Wald $=0.4, p=0.543 \mathrm{C} / \mathrm{P}-\mathrm{RIR}$ vs. $\mathrm{C}+\mathrm{P}-\mathrm{R})$. Age of menarche and body mass remained significant predictors for low lumbar spine BMD; with each one year increase in the age of menarche, the odds of low lumbar spine BMD increased 1.4 times (Wald=4.0, $p=0.045$ ), and with a lower body mass by one kilogram, the odds of low lumbar spine BMD decreased 1.1 times (Wald=5.3, $p=0.021$ ). Height and LMI remained significant predictors of low femoral neck BMD, demonstrating 1.3 times (Wald=5.6, $p=0.018$ ) and 3.6 times (Wald=5.4, $p=0.020$ ) greater odds of low BMD when lower by one unit, respectively. However, when controlling for cumulative menstrual status, age of menarche, body mass, height, and LMI, none of the variables were significant predictors of low hip BMD. 


\section{Discussion}

This study expands upon the classic work of Drinkwater et al. [3] who described the cumulative negative impact of past and current severe menstrual cycle disturbances on BMD in female athletes using DPA. The findings of Drinkwater et al. [3] are extended by exploring the impact of cumulative menstrual status on estimated bone geometry and strength from DXA, and consequently, we notably observed that exercising women with past and/or current menstrual irregularity had 4 to 8 times greater odds of low femoral neck CSMI or CSA when compared with exercising women with past and current regular menstrual cycles. This study also confirms the findings of Drinkwater et al.[3] that cumulative menstrual status is associated with lumbar spine BMD, such that a greater proportion of women who reported current and past irregular menstrual cycles had low lumbar spine BMD compared with those who reported current and past regular menstrual cycles.

As hypothesized, geometrical and strength measures of the femoral neck were similar among menstrual groups, supporting the findings of Duckham et al.[7] who reported similar femoral neck CSA, width, section modulus, and SI between women with and without a history of menstrual irregularity. It should be noted that the population of female endurance athletes in the aforementioned study [7] demonstrated greater mean femoral neck CSA, Z, and SI than our population of physically-active women when evaluated according to menstrual function. Studies to date, however, have failed to definitively determine the impact of menstrual cycle disturbances among athletes on femoral neck geometry. Duckham et al. [7] and Ackerman et al. [6] reported smaller femoral neck CSA among amenorrheic athletes compared with eumenorrheic athletes when categorized according to current self-reported menstrual status. However, similar to the findings presented herein, we previously reported no difference in femoral neck CSA and CSMI between amenorrheic and eumenorrheic exercising women who were categorized according to current menstrual status [12]. Contrary to our hypothesis, cumulative menstrual status was associated with one parameter of bone geometry, neck diameter, when assessing the proportion of women 
in each menstrual group that displayed relatively low femoral neck geometry and strength; however, the majority of geometrical and strength measures were not associated with cumulative menstrual status as we hypothesized. Interestingly, however, cumulative menstrual status was a significant predictor of low femoral neck CSMI, CSA, and diameter after controlling for body mass, height, and LMI. Because greater bone strength is achieved with larger bone size and the distribution of the bone mass farther away from the central axis, the results for CSMI and CSA suggest that episodes of menstrual irregularity, particularly those that occur during adolescence and young adulthood, may impair beneficial adaptations of bone geometry and compromise bone strength.

In agreement with our hypotheses, the C+P-IR women demonstrated significantly lower lumbar spine BMD compared with the C+P-R women; however, BMD at weight bearing sites, i.e., the femoral neck and total hip, was similar among groups. On the other hand, contrary to our hypotheses, the BMD of the C/P-RIR group was not significantly different from the BMD of both the C+P-IR and the C+P-R group at all sites. These results largely support the findings of other investigators, which demonstrated that female athletes with a history of menstrual irregularity had lower BMD [7] or Z-scores [28] at the lumbar spine but not at the femoral neck when compared with eumenorrheic athletes. Using a study design similar to that in the current study, Drinkwater et al.[3] also demonstrated that athletes with current and past menstrual irregularity and athletes with episodes of menstrual irregularity interspersed with periods of menstrual regularity had lower lumbar spine BMD than athletes who had consistently regular menstrual cycles. However, contrary to our findings and those of other investigators [7, 28], Drinkwater et al [3] reported that BMD at a weight-bearing site, the femoral shaft, was lower among athletes with current and past menstrual irregularity compared with athletes who had always had regular menstrual cycles (and compared with those who had episodes of amenorrhea/oligomenorrhea interspersed with period of eumenorrhea).

To our knowledge, the effects of cumulative menstrual status, represented by a categorization scheme based on the classic work of Drinkwater et al.[3], on femoral neck bone geometry have not been 
previously reported. Historically, the majority of studies focusing on the effects of menstrual cycle disturbances have naturally focused on BMD, the bone health variable clinically used to diagnose osteoporosis. However, with technological advances in bone health imaging, such as HSA, and greater accessibility to other modes of bone imaging, such as QCT, there has been an additional focus on bone geometry among female athletes with menstrual disturbances $[5-7,12,27,50]$. These advancements in the field of women's bone health are important due to the major influence that bone geometry has on overall bone health. As such, our results indicate that an accumulation of episodes of severe menstrual disturbances may compromise multiple components of bone strength, including not only BMD but also bone geometry.

Notably, exercising women who reported menstrual irregularity in the past and in the present had significantly greater odds of low CSMI and CSA at the femoral neck compared with those who had always had regular menstrual cycles. Further, those with irregular menses at some point during adolescence or adulthood had greater odds of low CSA compared with those who had always had regular menses. As such, the potential negative impact of severe menstrual cycle disturbances, even in the presence of episodes of regular menses, on bone geometry should not be disregarded. Of clinical importance is that a history of menstrual irregularities in conjunction with current menstrual irregularities, both of which can be identified simply through self-report or questionnaires, may indicate not only poor BMD [3,32] but also poor bone geometry, both of which may increase fracture risk $[26,33]$. As such, our results provide further evidence for the importance of clinical assessment of both current and past menstrual status when assessing an athlete's risk for the Female Athlete Triad and clearance to participate in sports as outlined in the 2014 Female Athlete Triad Coalition Consensus Statement [51]. Both BMD and bone geometry are key determinants of bone strength [33]. Notably, an increase in the size of the bone, thereby distributing the mass of the bone farther from the central axis, drastically increases bone strength, regardless of whether or not the thickness of the bone increases [34]. In fact, doubling the radius of the bone increases bone 
strength by a factor of 16 [34]. As such, a smaller femoral neck CSA and CSMI among female athletes with past and/or current menstrual disturbances when compared with athletes who have always had regular menstrual cycles may be detrimental to bone health by compromising bone strength and by adding to the negative effects that low $B M D[4,11,12,15]$ has on bone strength. Interestingly, the C/P-RIR group demonstrated the smallest proportion of women with low neck diameter compared with both the C+P-IR group and the C+P-R group, which had similar proportions of women with low neck diameter. More research in broader samples of female athletes is necessary to determine if neck diameter is influenced differently by the frequency, duration, and timing of amenorrheic episodes.

It is imperative to note that the women in this study ranged in age from 18-35 years, which represents the time frame when peak bone mass is being achieved or has already been achieved [24]. As such, the greater odds of smaller femoral neck CSMI and CSA among young women who have accumulated multiple episodes of severe menstrual disturbances throughout life compared with young women who have always had regular menstrual cycles is concerning. Presenting with compromised bone health during young adulthood, when the window for the accrual of bone mass is closed or nearly closed, potentially increases the risk for osteoporosis and fragility fractures [26], particularly during the postmenopausal years when some degree of bone loss is inevitable. Because there is no strong evidence that young women who have low bone mass as a result of menstrual disturbances are able to obtain optimal bone mass despite the restoration of normal menstrual function $[25,30,52,53]$, it is important that clinicians are aware of the role of cumulative menstrual status in bone health. Also, parents and health care providers of female athletes are recommended to give attention to episodes of irregular and absent menses to address the problem prior to severe bone health consequences.

Other significant predictors of low bone geometry and low BMD include easy-to-assess gynecological and anthropometric variables, thereby also serving as valuable clinical indicators of poor bone health in young, exercising women. Age of menarche (continuous variable) remained a significant 
independent predictor of low BMD at the lumbar spine after controlling for potential confounders. In agreement with other reports demonstrating that age of menarche has an inverse relation with BMD and late age of menarche ( $\geq 15$ years of age) is associated with low BMD [1, 12, 47, 48], these results indicate that the odds of having low BMD during adulthood increase with each subsequent year that passes during adolescence prior to menarche. In fact, due to its ease of assessment via self-report, late age of menarche, defined as menarche occurring on or after age 15 years, can be used as a valuable clinical tool to assess whether a young, exercising woman may have low lumbar spine BMD [1], which may predispose her to vertebral compression fractures later in life. The lumbar spine is particularly susceptible to loss of bone mass and deterioration of bone microarchitecture during aging and the onset of menopause due to its high proportion of trabecular bone [54]. Although age of menarche is a non-modifiable risk factor for low lumbar spine BMD among young women, knowledge of the risk may prompt appropriate action during young adulthood to improve or maintain BMD and minimize the likelihood of skeletal consequences in the future. The anthropometric variables, body mass and height, remained significant predictors of low lumbar spine BMD and low femoral neck CSMI, diameter, Z, and BMD, respectively, after controlling for potential confounders. The lower the weight and height, the greater the odds of low BMD and low femoral neck geometry and strength, respectively. These results are not surprising, given that low body weight is a known risk factor for low BMD [49] and fracture [55]. Possible reasons for the direct relation between body weight and bone health include greater mechanical force on the bone during weight-bearing activities and greater production of hormones with higher body weight [49]. Hormones, such as leptin and estrogen influence osteoblast and osteoclast activity and may correlate positively with body weight if greater adipose tissue mass is also present [49]. Further, our results demonstrate that LMI was a significant predictor of low femoral neck CSMI and BMD after adjusting for menstrual status and body size. The influence of muscle forces and therefore lean mass on BMD and bone geometry is well-established [1, 5, 6, 12, 56-58]. The mechanisms underlying the tight link between muscle and bone involve both biomechanical and 
endocrine factors [59]; however, the myriad pathways that link the two organs are complex and remain to be fully elucidated.

Notably, leanness sport and sport impact type were not associated with low femoral neck geometry or estimated strength or low BMD, contrary to reports from other investigators [1, 41, 46, 60, 61]. Undoubtedly, various loading impacts from different sports have an influence on bone integrity $[46,60,61]$ as do the factors related to leanness sports, such as menstrual cycle disturbances [40]. Other investigators studied primarily elite athletes or competitive athletes participating in specific sports [1, 41, 46, 60, 61]; whereas, our data was obtained from a sample of competitive and recreational female athletes. It is possible that the effect of sport type was not as robust in the present study due to the inclusion of recreational athletes who may spend less time than elite and/or competitive athletes participating in their primary sport, may have fewer years of participation in their primary sport, and may participate in a variety of sports, thereby making it more difficult to observe clear differences in indices of bone health when grouped according to primary sport type.

The strengths of the current study include the addition of HSA data, thereby expanding our knowledge of the influence of menstrual cycle disturbances in female athletes on bone health. Also, we used daily urinary measures of estrogen and progesterone to confirm self-reported current menstrual status. Due to the burden of daily assessment of reproductive hormones for at least one complete menstrual cycle or month, the majority of studies assessing bone health in female athletes rely on selfreport to obtain information about menstrual status. Although self-report is a necessary way to gather information about menstrual status, particularly menstrual history, it is still prone to inaccuracy. As such, a limitation of the present study is the self-report nature of past menstrual disturbances and $\mathrm{OC}$ use and the limited information gathered from participants about the nature and number of past menstrual irregularities. In addition, because our sample consists primarily of recreational athletes, the time spent in regular physical activity may be relatively minimal in some athletes (at least 120 hours per week) which could 
contribute to low CSMI and CSA as a result of minimal mechanical stimulation. Another limitation of this study is that the geometric and strength measures of the femoral neck are estimated using a twodimensional imaging technique; DXA is limited in its ability to accurately measure geometry and, therefore, strength due to positioning error and poor image quality [37].Finally, we recognize that calculating the femoral neck and total hip BMD Z-score of women $<20$ yrs of age relative to age 20 norms may underestimate bone health for those few women. Further research is needed to determine if the findings presented herein are also observed for geometrical and strength measures obtained using threedimensional imaging techniques such as QCT. In addition, evaluation of the utility of cumulative menstrual status to assess risk for low BMD in a clinical setting is also warranted.

\section{Conclusions}

In summary, the accumulation of menstrual cycle disturbances between menarche and young adulthood increases the odds of presenting with smaller femoral neck CSMI and CSA when compared with always having regular menstrual cycles, despite participation in regular physical activity. As such, when viewing our results in addition to those of other investigators [3], the occurrence of multiple episodes of amenorrhea or oligomenorrhea among exercising women has the potential to compromise multiple components of bone strength, i.e. BMD and bone geometry. Our results are of clinical utility due to the ease of assessment of cumulative menstrual status. A self-reported menstrual history that reveals multiple bouts of oligo/amenorrhea from menarche to young adulthood may indicate the presence of bones with smaller size than may be attained when regular menstrual cycles are exclusively experienced throughout the same time span. It must be emphasized that young adulthood is a time period when the accrual of bone mass has drastically slowed or ceased [23], thereby making it difficult to accrue additional bone mass at this stage of life in the event that bone accrual was negatively affected by menstrual cycle disturbances during the adolescent years. Compromised BMD and bone geometry during young adulthood, when the capability to improve bone health has drastically declined due to the slow rate or cessation of bone accrual, raises 
concern for lifelong health consequences, such as osteoporosis and fractures. Osteoporosis has been termed a "pediatric disease," although it primarily presents during the elderly years, due to the influence that bone accrual during the adolescent years has on future skeletal health [24]; therefore, appropriate education and intervention during adolescence and young adulthood are imperative to minimize the risk of skeletal consequences and compromised health later in life.

Conflicts of Interest: None

Acknowledgements: The U.S. Department of Defense, U.S. Army Medical Research and Materiel Command (Grant\#: PR054531) funded this research. 


\section{References}

[1] Gibbs JC, Nattiv A, Barrack MT, Williams NI, Rauh MJ, Nichols JF, De Souza MJ. Low bone density risk is higher in exercising women with multiple triad risk factors. Med Sci Sports Exerc 2014;46: 167-76.

[2] Drinkwater BL, Nilson K, Chesnut CH, 3rd, Bremner WJ, Shainholtz S, Southworth MB. Bone mineral content of amenorrheic and eumenorrheic athletes. N Engl J Med 1984;311: 277-81.

[3] Drinkwater BL, Bruemner B, Chesnut $\mathrm{CH}, 3 \mathrm{rd}$. Menstrual history as a determinant of current bone density in young athletes. JAMA 1990;263: 545-8.

[4] Christo K, Prabhakaran R, Lamparello B, Cord J, Miller KK, Goldstein MA, Gupta N, Herzog DB, Klibanski A, Misra M. Bone metabolism in adolescent athletes with amenorrhea, athletes with eumenorrhea, and control subjects. Pediatrics 2008;121: 1127-36.

[5] Ackerman KE, Nazem T, Chapko D, Russell M, Mendes N, Taylor AP, Bouxsein ML, Misra M. Bone microarchitecture is impaired in adolescent amenorrheic athletes compared with eumenorrheic athletes and nonathletic controls. J Clin Endocrinol Metab 2011;96: 3123-33.

[6] Ackerman KE, Pierce L, Guereca G, Slattery M, Lee H, Goldstein M, Misra M. Hip structural analysis in adolescent and young adult oligoamenorrheic and eumenorrheic athletes and nonathletes. $J$ Clin Endocrinol Metab 2013;98: 1742-9.

[7] Duckham RL, Peirce N, Bailey CA, Summers G, Cameron N, Brooke-Wavell K. Bone geometry according to menstrual function in female endurance athletes. Calcif Tissue Int 2013;92: 444-50.

[8] Duckham RL, Peirce N, Meyer C, Summers GD, Cameron N, Brooke-Wavell K. Risk factors for stress fracture in female endurance athletes: a cross-sectional study. BMJ Open 2012;2.

[9] Barrack MT, Gibbs JC, De Souza MJ, Williams NI, Nichols JF, Rauh MJ, Nattiv A. Higher incidence of bone stress injuries with increasing female athlete triad-related risk factors: a prospective multisite study of exercising girls and women. Am J Sports Med 2014;42: 949-58.

[10] Tenforde AS, Sayres LC, McCurdy ML, Sainani KL, Fredericson M. Identifying sex-specific risk factors for stress fractures in adolescent runners. Med Sci Sports Exerc 2013;45: 1843-51.

[11] Gibbs JC, Williams NI, De Souza MJ. Prevalence of individual and combined components of the female athlete triad. Med Sci Sports Exerc 2013;45: 985-96.

[12] Mallinson RJ, Williams NI, Hill BR, De Souza MJ. Body composition and reproductive function exert unique influences on indices of bone health in exercising women. Bone 2013;56: 91-100.

[13] West SL, Scheid JL, De Souza MJ. The effect of exercise and estrogen on osteoprotegerin in premenopausal women. Bone 2009;44: 137-44.

[14] Scheid JL, Toombs RJ, Ducher G, Gibbs JC, Williams NI, De Souza MJ. Estrogen and peptide YY are associated with bone mineral density in premenopausal exercising women. Bone 2011;49: 194-201.

[15] Rencken ML, Chesnut CH, 3rd, Drinkwater BL. Bone density at multiple skeletal sites in amenorrheic athletes. JAMA 1996;276: 238-40.

[16] De Souza MJ, Toombs RJ, Scheid JL, O'Donnell E, West SL, Williams NI. High prevalence of subtle and severe menstrual disturbances in exercising women: confirmation using daily hormone measures. Hum Reprod 2010;25: 491-503.

[17] Current evaluation of amenorrhea. Fertil Steril 2008;90: S219-25.

[18] Nattiv A, Loucks AB, Manore MM, Sanborn CF, Sundgot-Borgen J, Warren MP. American College of Sports Medicine position stand. The female athlete triad. Med Sci Sports Exerc 2007;39: 1867-82.

[19] Compston JE. Sex steroids and bone. Physiol Rev 2001;81: 419-447.

[20] De Souza MJ, West SL, Jamal SA, Hawker GA, Gundberg CM, Williams NI. The presence of both an energy deficiency and estrogen deficiency exacerbate alterations of bone metabolism in exercising women. Bone 2008;43: 140-8. 
[21] Russell M, Misra M. Influence of ghrelin and adipocytokines on bone mineral density in adolescent female athletes with amenorrhea and eumenorrheic athletes. Med Sport Sci 2010;55: 103-13.

[22] Nelson ME, Fisher EC, Catsos PD, Meredith CN, Turksoy RN, Evans WJ. Diet and bone status in amenorrheic runners. Am J Clin Nutr 1986;43: 910-6.

[23] Theintz G, Buchs B, Rizzoli R, Slosman D, Clavien H, Sizonenko PC, Bonjour JP. Longitudinal monitoring of bone mass accumulation in healthy adolescents: evidence for a marked reduction after 16 years of age at the levels of lumbar spine and femoral neck in female subjects. J Clin Endocrinol Metab 1992;75: 1060-5.

[24] Bonjour JP, Chevalley T. Pubertal timing, bone acquisition, and risk of fracture throughout life. Endocr Rev 2014;35: 820-47.

[25] Keen AD, Drinkwater BL. Irreversible bone loss in former amenorrheic athletes. Osteoporos Int 1997;7: 311-5.

[26] Rizzoli R, Bianchi ML, Garabedian M, McKay HA, Moreno LA. Maximizing bone mineral mass gain during growth for the prevention of fractures in the adolescents and the elderly. Bone 2010;46: 294-305.

[27] Ducher G, Eser P, Hill B, Bass S. History of amenorrhoea compromises some of the exerciseinduced benefits in cortical and trabecular bone in the peripheral and axial skeleton: a study in retired elite gymnasts. Bone 2009;45: 760-7.

[28] Dimitriou L, Weiler R, Lloyd-Smith R, Turner A, Heath L, James N, Reid A. Bone mineral density, rib pain and other features of the female athlete triad in elite lightweight rowers. BMJ Open 2014;4: e004369.

[29] Tenforde AS, Fredericson M, Sayres LC, Cutti P, Sainani KL. Identifying Sex-Specific Risk Factors for Low Bone Mineral Density in Adolescent Runners. Am J Sports Med 2015.

[30] Hind K, Zanker C, Truscott J. Five-year follow-up investigation of bone mineral density by age in premenopausal elite-level long-distance runners. Clin J Sport Med 2011;21: 521-9.

[31] Grimston SK, Sanborn CF, Miller PD, Huffer WE. The application of historical data for evaluation of osteopenia in female runners: the menstrual index. Clinical Sports Medicine 1990;2: 108-118.

[32] Lloyd T, Myers C, Buchanan JR, Demers LM. Collegiate women athletes with irregular menses during adolescence have decreased bone density. Obstet Gynecol 1988;72: 639-42.

[33] Fonseca H, Moreira-Goncalves D, Coriolano HJ, Duarte JA. Bone quality: the determinants of bone strength and fragility. Sports Med 2014;44: 37-53.

[34] Seeman E. Bone quality: the material and structural basis of bone strength. J Bone Miner Metab 2008;26: 1-8.

[35] Yoshikawa T, Turner CH, Peacock M, Slemenda CW, Weaver CM, Teegarden D, Markwardt P, Burr DB. Geometric structure of the femoral neck measured using dual-energy x-ray absorptiometry. J Bone Miner Res 1994;9: 1053-64.

[36] Beck TJ, Broy SB. Measurement of Hip Geometry-Technical Background. J Clin Densitom 2015;18: 331-7.

[37] Beck TJ. Extending DXA beyond bone mineral density: understanding hip structure analysis. Curr Osteoporos Rep 2007;5: 49-55.

[38] De Souza MJ, Miller BE, Loucks AB, Luciano AA, Pescatello LS, Campbell CG, Lasley BL. High frequency of luteal phase deficiency and anovulation in recreational women runners: blunted elevation in follicle-stimulating hormone observed during luteal-follicular transition. J Clin Endocrinol Metab 1998;83: 4220-32.

[39] Sundgot-Borgen J, Larsen S. Pathogenic weight-control methods and self-reported eating disorders in female elite athletes and controls. Scandinavian Journal of Medicine and Science in Sports 1993;3: 150-155. 
[40] Torstveit MK, Sundgot-Borgen J. The female athlete triad: are elite athletes at increased risk? Med Sci Sports Exerc 2005;37: 184-93.

[41] Torstveit MK, Sundgot-Borgen J. Low bone mineral density is two to three times more prevalent in non-athletic premenopausal women than in elite athletes: a comprehensive controlled study. $\mathrm{Br} \mathrm{J}$ Sports Med 2005;39: 282-7; discussion 282-7.

[42] Groothausen J, Siemer H, Kemper HCG, Twisk J, Welten DC. Influence of peak strain on lumbar bone mineral density: An analysis of 15-year physical activity in young males and females. Pediatric Exercise Science 1997;9: 159-173.

[43] Carey JJ, Delaney MF, Love TE, Richmond BJ, Cromer BA, Miller PD, Manilla-McIntosh M, Lewis SA, Thomas CL, Licata AA. DXA-generated Z-scores and T-scores may differ substantially and significantly in young adults. J Clin Densitom 2007;10: 351-8.

[44] Duckham RL, Brooke-Wavell K, Summers GD, Cameron N, Peirce N. Stress fracture injury in female endurance athletes in the United Kingdom: A 12-month prospective study. Scand J Med Sci Sports 2015;25: 854-9.

[45] Field A. Chapter 10: Comparing several means: ANOVA (GLM 1). In: Discovering Statistics Using SPSS, 3rd ed. London: Sage Publications; 2009, p. 347-394.

[46] Nikander R, Sievanen H, Heinonen A, Kannus P. Femoral neck structure in adult female athletes subjected to different loading modalities. J Bone Miner Res 2005;20: 520-8.

[47] Chevalley T, Bonjour JP, Ferrari S, Rizzoli R. Influence of age at menarche on forearm bone microstructure in healthy young women. J Clin Endocrinol Metab 2008;93: 2594-601.

[48] Chevalley T, Bonjour JP, Ferrari S, Rizzoli R. Deleterious effect of late menarche on distal tibia microstructure in healthy 20-year-old and premenopausal middle-aged women. J Bone Miner Res 2009;24: 144-52.

[49] Bainbridge KE, Sowers M, Lin X, Harlow SD. Risk factors for low bone mineral density and the 6year rate of bone loss among premenopausal and perimenopausal women. Osteoporos Int 2004;15: 43946.

[50] Ackerman KE, Putman M, Guereca G, Taylor AP, Pierce L, Herzog DB, Klibanski A, Bouxsein M, Misra M. Cortical microstructure and estimated bone strength in young amenorrheic athletes, eumenorrheic athletes and non-athletes. Bone 2012;51: 680-7.

[51] De Souza MJ, Nattiv A, Joy E, Misra M, Williams NI, Mallinson RJ, Gibbs JC, Olmsted M, Goolsby M, Matheson G. 2014 Female Athlete Triad Coalition Consensus Statement on Treatment and Return to Play of the Female Athlete Triad: 1st International Conference held in San Francisco, California, May 2012 and 2nd International Conference held in Indianapolis, Indiana, May 2013. Br J Sports Med 2014;48: 289.

[52] Drinkwater BL, Nilson K, Ott S, Chesnut CH, 3rd. Bone mineral density after resumption of menses in amenorrheic athletes. JAMA 1986;256: 380-2.

[53] Jonnavithula S, Warren MP, Fox RP, Lazaro Ml. Bone density is compromised in amenorrheic women despite return of menses: a 2-year study. Obstet Gynecol 1993;81: 669-74.

[54] Riggs BL, Melton LJ, Robb RA, Camp JJ, Atkinson EJ, McDaniel L, Amin S, Rouleau PA, Khosla $\mathrm{S}$. A population-based assessment of rates of bone loss at multiple skeletal sites: evidence for substantial trabecular bone loss in young adult women and men. J Bone Miner Res 2008;23: 205-14.

[55] Compston JE, Flahive J, Hosmer DW, Watts NB, Siris ES, Silverman S, Saag KG, Roux C, Rossini M, Pfeilschifter J, Nieves JW, Netelenbos JC, March L, LaCroix AZ, Hooven FH, Greenspan SL, Gehlbach SH, Diez-Perez A, Cooper C, Chapurlat RD, Boonen S, Anderson FA, Jr., Adami S, Adachi JD. Relationship of weight, height, and body mass index with fracture risk at different sites in postmenopausal women: the Global Longitudinal study of Osteoporosis in Women (GLOW). J Bone Miner Res 2014;29: 487-93. 
[56] Petit MA, Beck TJ, Lin HM, Bentley C, Legro RS, Lloyd T. Femoral bone structural geometry adapts to mechanical loading and is influenced by sex steroids: the Penn State Young Women's Health Study. Bone 2004;35: 750-9.

[57] Robling AG. Is bone's response to mechanical signals dominated by muscle forces? Med Sci Sports Exerc 2009;41: 2044-9.

[58] Burr DB. Muscle strength, bone mass, and age-related bone loss. J Bone Miner Res 1997;12: $1547-51$.

[59] Cianferotti L, Brandi ML. Muscle-bone interactions: basic and clinical aspects. Endocrine 2014;45: 165-77.

[60] Nikander R, Sievanen H, Uusi-Rasi K, Heinonen A, Kannus P. Loading modalities and bone structures at nonweight-bearing upper extremity and weight-bearing lower extremity: a PQCT study of adult female athletes. Bone 2006;39: 886-94.

[61] Nikander R, Kannus P, Rantalainen T, Uusi-Rasi K, Heinonen A, Sievanen H. Cross-sectional geometry of weight-bearing tibia in female athletes subjected to different exercise loadings. Osteoporos Int 2010;21: 1687-94. 
Figure Legends for " Current and past menstrual status is an important determinant of femoral neck geometry in exercising women"

Figure 1. A) Proportion of women with low femoral neck CSMI $\left(<9,619 \mathrm{~mm}^{4}\right.$, black bars $)$ and high CSMI $\left(\geq 9,619 \mathrm{~mm}^{4}\right.$, white bars) in each menstrual group. $X^{2}=3.856, p=0.146$. B) Proportion of women with low femoral neck CSA ( $<155 \mathrm{~mm}^{2}$, black bars) and high CSA $\left(\geq 155 \mathrm{~mm}^{2}\right.$, white bars) in each menstrual group. $X^{2}=4.520, p=0.111$. C) Proportion of women with low femoral neck $\mathrm{SI}(<1.749$, black bars) and high SI $\left(\geq 1.749\right.$, white bars) in each menstrual group. $X^{2}=1.317, p=0.518$. D) Proportion of women with low FN diameter ( $<30.5 \mathrm{~mm}$, black bars) and high diameter ( $\geq 30.5 \mathrm{~mm}$, white bars) in each menstrual group. $X^{2}=$ 10.018, $p=0.007$. E) Proportion of women with low FN section modulus (Z) $\left(<623.4 \mathrm{~mm}^{3}\right.$, black bars) and high $Z$ ( $\geq 623.4 \mathrm{~mm}^{3}$, white bars) in each menstrual group. $X^{2}=2.466, p=0.310$.

C+P-R: current and past regular menses; C/P-RIR: current or past irregular menses; C+P-IR: current and past irregular menses; CSMI: cross-sectional moment of inertia; CSA: cross-sectional area; SI: strength index

Figure 2. Proportion of women with low BMD (Z-score <-1, black bars) and normal BMD (Z-score $\geq-1$, white bars) in each menstrual group. A) Proportion of women with low lumbar spine BMD. $X^{2}=10.252$, $p=0.006$. B) Proportion of women with low femoral neck BMD. Fisher's exact test $p$-value $=0.189$. C) Proportion of women with low total hip BMD. Fisher's exact test $p$-value=1.000 Fisher's exact test, which has no test statistic was used for femoral neck BMD and total hip BMD due to expected cell counts $<5$. C+P-R: current and past regular menses; C/P-RIR: current or past irregular menses; C+P-IR: current and past irregular menses

Figure 3. Forest plots of multivariable logistic regression models for low (below median) femoral neck geometry and strength. Boxes indicate adjusted odds ratio and lines indicate $95 \%$ confidence intervals. Final model $\mathrm{R}^{2}$ (Nagelkerke) $=0.550$ for FN CSMI, 0.283 for FN CSA, 0.037 for FN SI, 0.363 for FN Diameter, 0.337 for FN Section Modulus.

C+P-R: current and past regular menses; C/P-RIR: current or past irregular menses; C+P-IR: current and past irregular menses. C+P-R is the reference category.

OR: odds ratio; FN: femoral neck; CSMI: cross-sectional moment of inertia; CSA: cross-sectional area; SI: strength index.

${ }^{*} p<0.05$ Wald statistic; ${ }^{* *} p<0.01$ Wald statistic; ${ }^{* * *} p<0.001$ Wald statistic 
Figure 4. Forest plots of multivariate logistic regression models for low BMD, defined as Z-score $<-1$. Boxes indicate adjusted odds ratio and lines indicate $95 \%$ confidence intervals.

Final model R2 (Nagelkerke) $=0.322$ for LS BMD, 0.314 for FN BMD, 0.074 for Hip BMD.

C+P-R: current and past regular menses; C/P-RIR: current or past irregular menses; $C+P-I R$ : current and past irregular menses. C+P-R is the reference category.

OR: odds ratio; BMD: bone mineral density; LS: lumbar spine; FN: femoral neck ${ }^{*} p<0.05$ Wald statistic; ${ }^{* *} p<0.01$ Wald statistic; ${ }^{* * *} p<0.001$ Wald statistic 
A

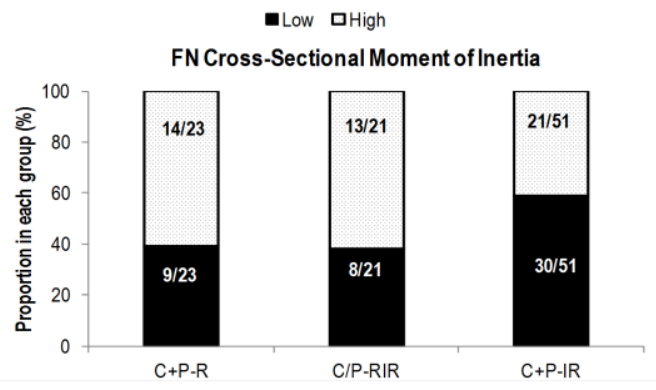

B

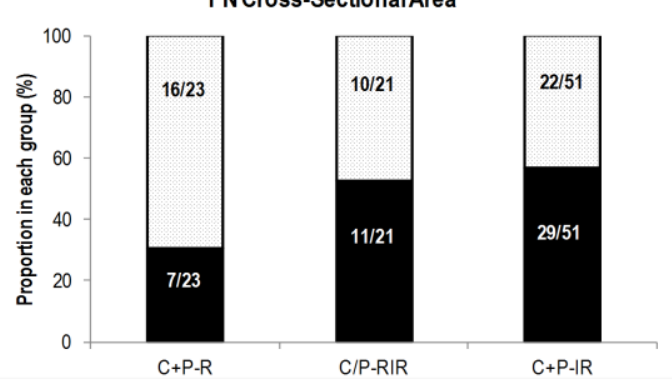

C

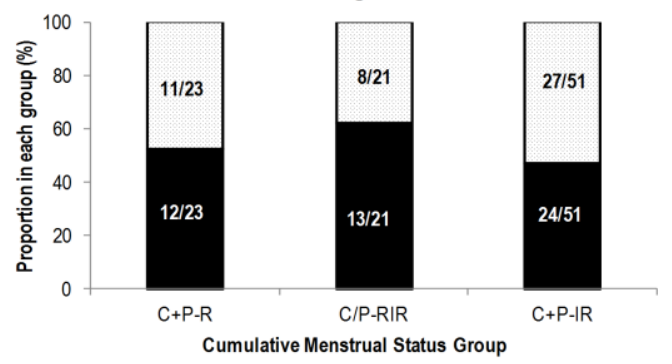

D

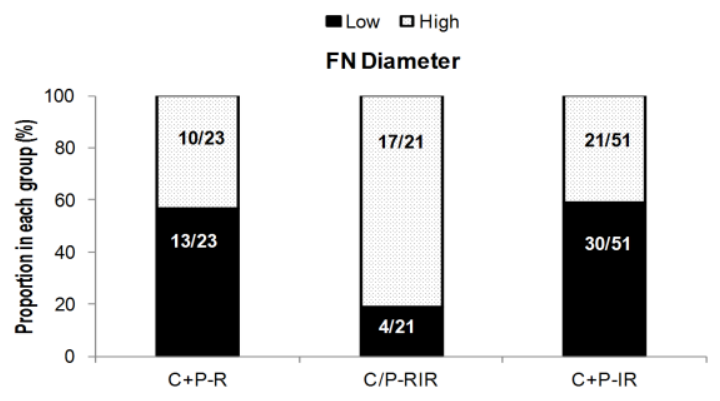

E

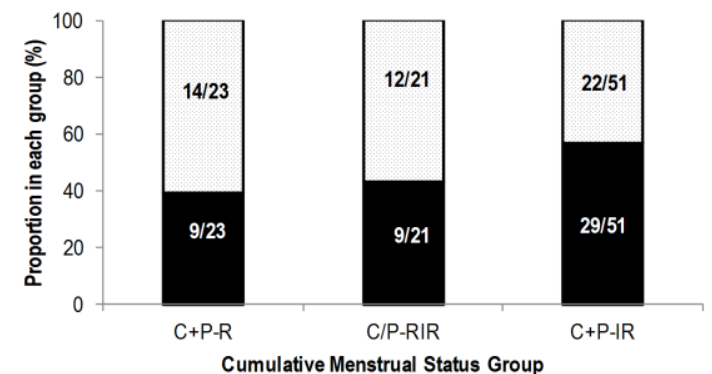


A

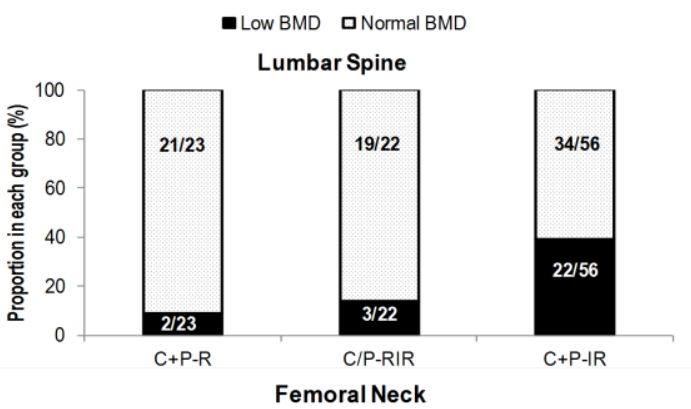

B

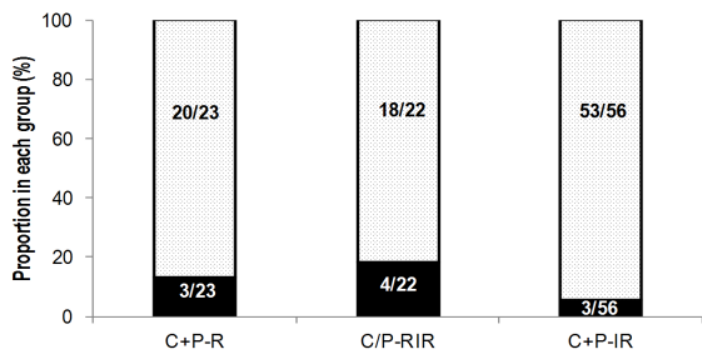

C

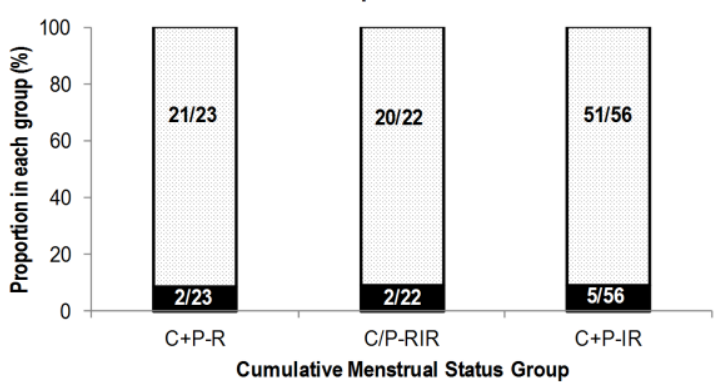



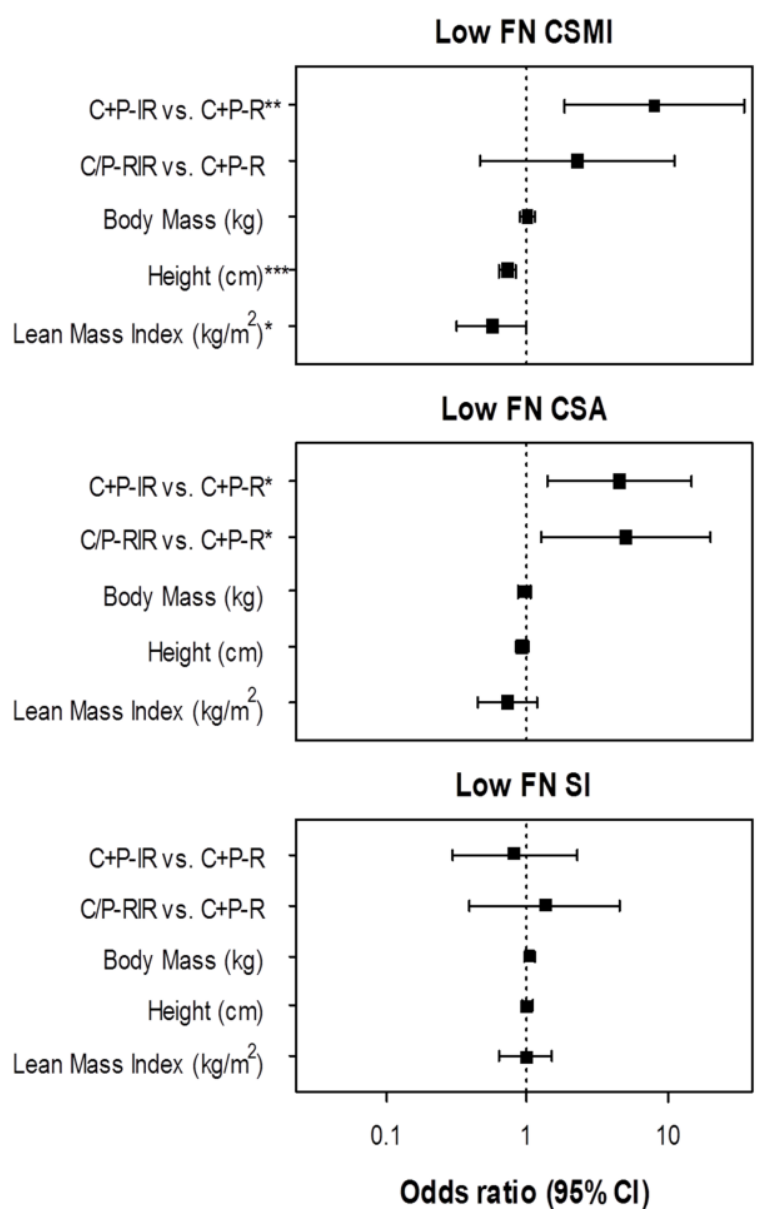

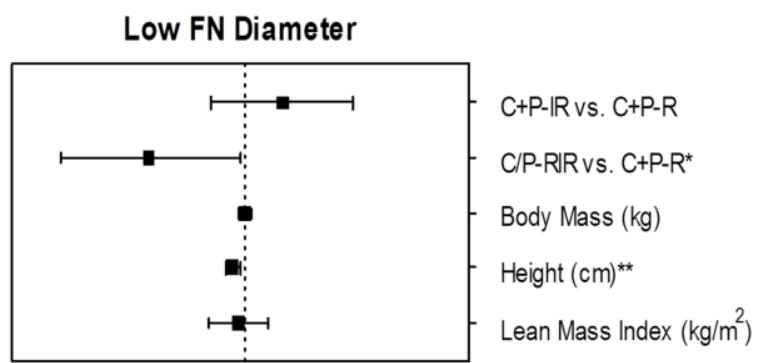

Low FN Section Modulus

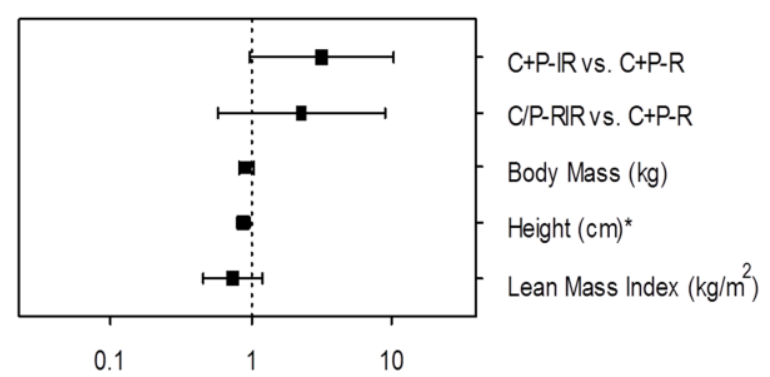

Odds ratio $(95 \% \mathrm{Cl})$ 

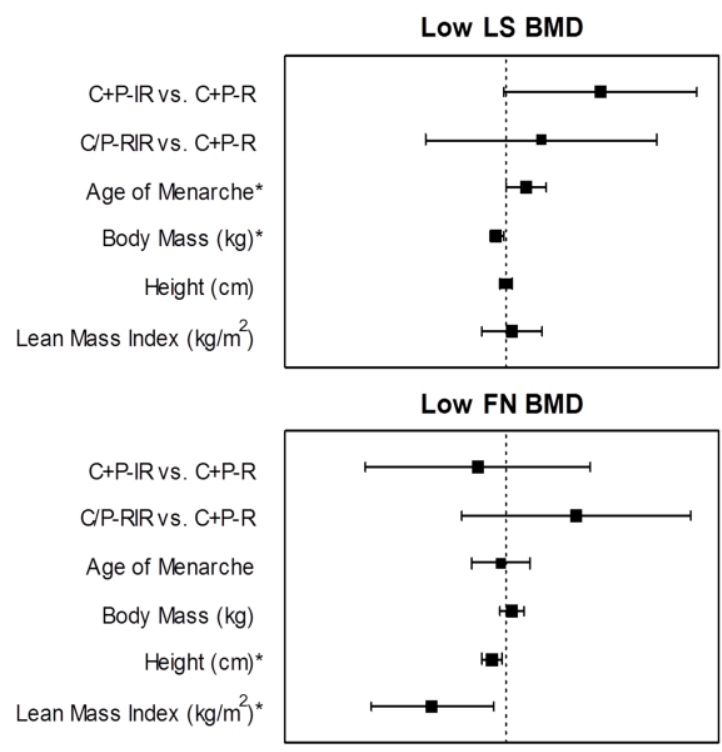

Low Hip BMD

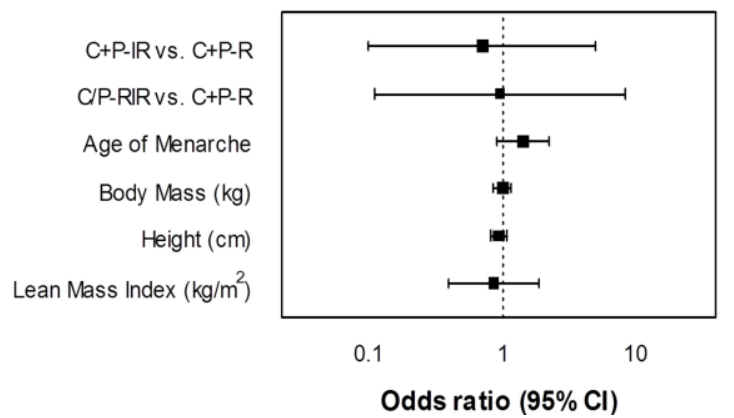


Table 1A. Descriptive characteristics of exercising women used for HSA analyses ( $n=95)$.

\begin{tabular}{|c|c|c|c|c|}
\hline & $\begin{array}{l}C+P-R \\
(n=23)\end{array}$ & $\begin{array}{c}\text { C/P-RIR } \\
(n=21)\end{array}$ & $\begin{array}{l}C+P-I R \\
(n=51)\end{array}$ & P-value \\
\hline \multicolumn{5}{|l|}{ Demographics } \\
\hline Age (yrs) & $24.1 \pm 1.1$ & $22.6 \pm 0.8$ & $21.1 \pm 0.4^{a}$ & 0.018 \\
\hline Height (cm) & $163.3 \pm 1.2$ & $166.8 \pm 1.5$ & $165.9 \pm 0.9$ & 0.151 \\
\hline Body Mass (kg) & $56.9 \pm 1.1$ & $60.4 \pm 1.4$ & $57.3 \pm 1.1$ & 0.145 \\
\hline $\mathrm{BMI}\left(\mathrm{kg} / \mathrm{m}^{2}\right)$ & $21.3 \pm 0.4$ & $21.7 \pm 0.4$ & $20.8 \pm 0.3$ & 0.207 \\
\hline Age of Menarche (yrs) & $12.4 \pm 0.2$ & $13.1 \pm 0.3$ & $13.6 \pm 0.2^{b}$ & 0.010 \\
\hline Gynecological Age (yrs) & $11.7 \pm 1.1$ & $9.5 \pm 0.8$ & $7.5 \pm 0.5^{b}$ & 0.001 \\
\hline Physical Activity (min/wk) & $418 \pm 51$ & $481 \pm 93$ & $579 \pm 64$ & 0.271 \\
\hline \multicolumn{5}{|l|}{ Body Composition } \\
\hline Body Fat (\%) & $26.5 \pm 0.9$ & $26.6 \pm 0.7$ & $24.3 \pm 0.8$ & 0.062 \\
\hline Fat Mass $(\mathrm{kg})$ & $15.2 \pm 0.7$ & $16.0 \pm 0.6$ & $14.0 \pm 0.6$ & 0.127 \\
\hline Lean Mass $(\mathrm{kg})$ & $39.5 \pm 0.8$ & $42.0 \pm 1.0$ & $40.9 \pm 0.7$ & 0.189 \\
\hline Lean Mass Index $\left(\mathrm{kg} / \mathrm{m}^{2}\right)$ & $14.8 \pm 0.3$ & $15.1 \pm 0.3$ & $14.8 \pm 0.2$ & 0.739 \\
\hline
\end{tabular}

${ }^{a} \mathrm{C}+\mathrm{P}-\mathrm{IR}$ vs. $\mathrm{C}+\mathrm{P}-\mathrm{R}, \mathrm{p}<0.05$

${ }^{b} C+P-I R$ vs. $C+P-R, p<0.01$

$\mathrm{C}+\mathrm{P}-\mathrm{R}$ : current and past regular menses; C/P-RIR: current or past irregular menses; $\mathrm{C}+\mathrm{P}-\mathrm{IR}$ : current and past irregular menses

Data are mean \pm SEM. 
Table 1B. Descriptive characteristics of exercising women used for BMD analyses ( $n=101)$.

\begin{tabular}{|c|c|c|c|c|}
\hline & $\begin{array}{l}C+P-R \\
(n=23)\end{array}$ & $\begin{array}{l}\text { C/P-RIR } \\
(n=22)\end{array}$ & $\begin{array}{l}C+P-I R \\
(n=56)\end{array}$ & P-value \\
\hline \multicolumn{5}{|l|}{ Demographics } \\
\hline Age (yrs) & $24.1 \pm 1.1$ & $22.6 \pm 0.7$ & $20.9 \pm 0.4^{b}$ & 0.006 \\
\hline Height (cm) & $163.3 \pm 1.2$ & $166.8 \pm 1.5$ & $166.4 \pm 0.9$ & 0.105 \\
\hline Body Mass (kg) & $56.9 \pm 1.1$ & $60.1 \pm 1.3$ & $57.4 \pm 1.0$ & 0.212 \\
\hline $\mathrm{BMI}\left(\mathrm{kg} / \mathrm{m}^{2}\right)$ & $21.3 \pm 0.4$ & $21.6 \pm 0.4$ & $20.7 \pm 0.3$ & 0.191 \\
\hline Age of Menarche (yrs) & $12.4 \pm 0.2$ & $13.1 \pm 0.3$ & $13.6 \pm 0.2^{a}$ & 0.013 \\
\hline Gynecological Age (yrs) & $11.7 \pm 1.1$ & $9.5 \pm 0.7$ & $7.4 \pm 0.4^{\mathrm{c}, \mathrm{d}}$ & $<0.001$ \\
\hline Physical Activity (min/wk) & $418 \pm 51$ & $478 \pm 88$ & $579 \pm 59$ & 0.175 \\
\hline \multicolumn{5}{|l|}{ Body Composition } \\
\hline Body Fat (\%) & $26.5 \pm 0.9$ & $26.3 \pm 0.8$ & $24.1 \pm 0.7$ & 0.071 \\
\hline Fat Mass $(\mathrm{kg})$ & $15.2 \pm 0.7$ & $15.8 \pm 0.7$ & $14.0 \pm 0.6$ & 0.145 \\
\hline Lean Mass $(\mathrm{kg})$ & $39.5 \pm 0.8$ & $41.8 \pm 1.0$ & $41.0 \pm 0.6$ & 0.202 \\
\hline Lean Mass Index $\left(\mathrm{kg} / \mathrm{m}^{2}\right)$ & $14.8 \pm 0.3$ & $15.0 \pm 0.2$ & $14.8 \pm 0.2$ & 0.744 \\
\hline
\end{tabular}

${ }^{a} C+P-I R$ vs. $C+P-R, p<0.05$

${ }^{b} \mathrm{C}+\mathrm{P}-\mathrm{IR}$ vs. $\mathrm{C}+\mathrm{P}-\mathrm{R}, \mathrm{p}<0.01$

${ }^{c} \mathrm{C}+\mathrm{P}-\mathrm{IR}$ vs. $\mathrm{C}+\mathrm{P}-\mathrm{R}, \mathrm{p}<0.001$

${ }^{d} C+P-I R$ vs. $C / P-R I R, p<0.05$

C+P-R: current and past regular menses; C/P-RIR: current or past irregular menses; $C+P-I R$ : current and past irregular menses

Data are mean \pm SEM. 
Table 2A. Categorization of sports as "leanness" or "non-leanness" activities.

\begin{tabular}{|c|c|c|c|c|c|}
\hline \multicolumn{3}{|c|}{ Leanness Sports $(n=80)$} & \multicolumn{3}{|c|}{ Non-Leanness Sports $(n=21)$} \\
\hline Endurance & Aesthetic & Antigravitation & Technical & Ball Game & Power \\
\hline Cycling ( $n=6)$ & $\begin{array}{c}\text { Dancing } \\
(n=6)\end{array}$ & $\begin{array}{c}\text { Aerial } \\
\text { Acrobatics } \\
(n=1)\end{array}$ & $\begin{array}{l}\text { Pentathlon } \\
\quad(n=1)\end{array}$ & Soccer $(n=4)$ & $\begin{array}{l}\text { Weight/Strength } \\
\text { Training }(n=3)\end{array}$ \\
\hline Triathlon $(n=1)$ & $\begin{array}{l}\text { Cheerleading } \\
\quad(n=1)\end{array}$ & & $\begin{array}{l}\text { Martial Arts } \\
\quad(n=1)\end{array}$ & Rugby $(n=1)$ & Sprinting $(n=1)$ \\
\hline $\begin{array}{l}\text { Distance Running } \\
\quad(\mathrm{n}=44)\end{array}$ & $\begin{array}{c}\text { Gymnastics } \\
(n=1)\end{array}$ & & & Tennis $(n=3)$ & Pilates $(n=1)$ \\
\hline Swimming $(n=5)$ & & & & Field Hockey $(n=3)$ & $\begin{array}{c}\text { Strength } \\
\text { Training/Aerobics } \\
(\mathrm{n}=1)\end{array}$ \\
\hline Aerobics $(n=1)$ & & & & Softball $(n=1)$ & \\
\hline $\begin{array}{c}\text { Aerobic (Cardio) at } \\
\text { Gym }(n=11)\end{array}$ & & & & Volleyball $(n=1)$ & \\
\hline \multicolumn{6}{|l|}{ Rowing ( $n=2$ ) } \\
\hline Walking $(n=1)$ & & & & & \\
\hline
\end{tabular}

Table 2B. Categorization of sports according to type of impact.

\begin{tabular}{ccc}
\hline Low Impact $(n=12)$ & Moderate Impact $(n=73)$ & High Impact $(n=16)$ \\
\hline \hline Cycling $(n=6)$ & Distance Running $(n=44)$ & Tennis $(n=3)$ \\
Swimming $(n=5)$ & Triathlon $(n=1)$ & Gymnastics $(n=1)$ \\
Aerial Acrobatics $(n=1)$ & Dancing $(n=6)$ & Soccer $(n=4)$ \\
& Rowing $(n=2)$ & Softball $(n=1)$ \\
& Field Hockey $(n=3)$ & Cheerleading $(n=1)$ \\
& Martial Arts $(n=1)$ & Rugby $(n=1)$ \\
& Pentathlon $(n=1)$ & Weight/Strength Training $(n=3)$ \\
& Pilates $(n=1)$ & Sprinting $(n=1)$ \\
& Strength Training/Aerobics $(n=1)$ & \\
Aerobic (Cardio) at Gym $(n=11)$ & \\
& Aerobics $(n=1)$ & \\
& Walking $(n=1)$ & \\
\hline \hline
\end{tabular}


Table 3A. Hip strength analysis characteristics.

\begin{tabular}{lcccc}
\hline & $\begin{array}{c}\text { C+P-R } \\
(\mathbf{n = 2 3})\end{array}$ & $\begin{array}{c}\text { C/P-RIR } \\
(\mathbf{n = 2 1 )}\end{array}$ & $\begin{array}{c}\text { C+P-IR } \\
(\mathbf{n}=51)\end{array}$ & P-value \\
\hline \hline Femoral Neck Geometry & & & & \\
$\quad$ CSMI $\left(\mathrm{mm}^{4}\right)$ & $9689 \pm 360$ & $9906 \pm 439$ & $9349 \pm 293$ & 0.389 \\
CSA $\left(\mathrm{mm}^{2}\right)$ & $157.1 \pm 3.9$ & $152.5 \pm 4.9$ & $153.5 \pm 2.8$ & 0.253 \\
Strength Index & $1.72 \pm 0.04$ & $1.62 \pm 0.05$ & $1.77 \pm 0.06$ & 0.143 \\
Neck Diameter (mm) & $30.3 \pm 0.4$ & $31.4 \pm 0.3$ & $30.3 \pm 0.3$ & $\mathbf{0 . 0 4 5}$ \\
Section Modulus $\left(\mathrm{mm}^{3}\right)$ & $648.2 \pm 22.9$ & $631.7 \pm 24.9$ & $621.9 \pm 16.0$ & 0.652 \\
\hline \hline
\end{tabular}

C+P-R: current and past regular menses; C/P-RIR: current or past irregular menses; C+P-IR: current and past irregular menses ; BMD: bone mineral density; CSMI: cross sectional moment of inertia; CSA: cross-sectional area. Data are mean \pm SEM.

Table 3B. Bone mineral density characteristics.

\begin{tabular}{lcccc}
\hline & $\begin{array}{c}\text { C+P-R } \\
(\mathbf{n = 2 3})\end{array}$ & $\begin{array}{c}\text { C/P-RIR } \\
(\mathbf{n}=22)\end{array}$ & $\begin{array}{c}\text { C+P-IR } \\
(\mathbf{n}=56)\end{array}$ & P-value \\
\hline \hline Bone Mineral Density & & & & \\
Lumbar spine (L1-L4) BMD $\left(\mathrm{g} / \mathrm{cm}^{2}\right)$ & $1.192 \pm 0.026$ & $1.147 \pm 0.021$ & $1.096 \pm 0.017^{\mathrm{a}}$ & $\mathbf{0 . 0 0 2}$ \\
Lumbar spine (L1-L4) Z-score & $0.3 \pm 0.2$ & $-0.2 \pm 0.17$ & $-0.6 \pm 0.1 \mathrm{a}$ & $\mathbf{0 . 0 0 1}$ \\
Femoral Neck BMD (g/cm²) & $1.072 \pm 0.025$ & $1.020 \pm 0.030$ & $1.053 \pm 0.018$ & 0.413 \\
Femoral Neck Z-score & $0.8 \pm 0.2$ & $0.3 \pm 0.3$ & $0.6 \pm 0.1$ & 0.380 \\
Total Hip BMD (g/cm $\left.{ }^{2}\right)$ & $1.080 \pm 0.025$ & $1.035 \pm 0.027$ & $1.048 \pm 0.018$ & 0.253 \\
Total Hip Z-score & $0.7 \pm 0.2$ & $0.3 \pm 0.2$ & $0.4 \pm 0.1$ & 0.516 \\
\hline \hline
\end{tabular}

a C+P-IR vs. C+P-R, $p<0.01$

C+P-R: current and past regular menses; C/P-RIR: current or past irregular menses; C+P-IR: current and past irregular menses ; BMD: bone mineral density; CSMI: cross sectional moment of inertia; CSA: cross-sectional area. Data are mean \pm SEM. 
Table 4. Crude odds ratios and 95\% confidence intervals for low (below median) femoral neck geometry and low BMD, defined as Z-score <-1, at multiple sites.

\begin{tabular}{|c|c|c|c|c|c|}
\hline & $\begin{array}{l}\text { Low FN CSMI } \\
\text { OR }(95 \% \mathrm{Cl})\end{array}$ & $\begin{array}{l}\text { Low FN CSA } \\
\text { OR }(95 \% \mathrm{Cl})\end{array}$ & $\begin{array}{l}\text { Low FN SI } \\
\text { OR }(95 \% \mathrm{Cl})\end{array}$ & $\begin{array}{c}\text { Low FN Diameter } \\
\text { OR }(95 \% \mathrm{Cl})\end{array}$ & $\begin{array}{c}\text { Low FN Section Modulus } \\
\text { OR }(95 \% \mathrm{Cl})\end{array}$ \\
\hline \multicolumn{6}{|l|}{$\begin{array}{l}\text { Cumulative Menstrual } \\
\text { Status }^{\text {a }}\end{array}$} \\
\hline$C+P-I R$ vs. $C+P-R$ & $2.22(0.81,6.08)$ & $3.01^{*}(1.06,8.58)$ & $0.82(0.30,2.18)$ & $1.10(0.41,2.97)$ & $2.05(0.75,5.60)$ \\
\hline C/P-RIR vs. C+P-R & $0.96(0.28,3.23)$ & $2.51(0.73,8.64)$ & $1.49(0.45,4.96)$ & $0.18^{*}(0.05,0.71)$ & $1.17(0.35,3.89)$ \\
\hline Age of Menarche (yrs) & $1.03(0.80,1.33)$ & $1.25(0.96,1.64)$ & $1.04(0.81,1.35)$ & $1.17(0.90,1.51)$ & $1.09(0.84,1.41)$ \\
\hline Body Mass (kg) & $0.85^{* * *}(0.79,0.93)$ & $\mathbf{0 . 8 9 * *}(0.83,0.96)$ & $1.04(0.98,1.10)$ & $0.91^{* *}(0.85,0.97)$ & $0.86^{* * *}(0.79,0.93)$ \\
\hline Height (cm) & $\mathbf{0 . 7 9 ^ { * * * }}(0.72,0.87)$ & $0.91^{* *}(0.85,0.98)$ & $1.02(0.96,1.09)$ & $\mathbf{0 . 8 6 ^ { * * * }}(0.79,0.93)$ & $0.88^{\star *}(0.82,0.95)$ \\
\hline Body Mass Index $\left(\mathrm{kg} / \mathrm{m}^{2}\right)$ & $0.91(0.74,1.10)$ & $\mathbf{0 . 8 0 ^ { * }}(0.65,0.98)$ & $1.10(0.90,1.34)$ & $0.97(0.80,1.18)$ & $\mathbf{0 . 7 8 ^ { * }}(0.63,0.96)$ \\
\hline Lean Body Mass $(\mathrm{kg})$ & $\mathbf{0 . 7 3} 3^{* * *}(0.64,0.84)$ & $\mathbf{0 . 8 4 ^ { * * }}(0.75,0.93)$ & $1.04(0.95,1.14)$ & $0.86^{* *}(0.77,0.95)$ & $\mathbf{0 . 7 8 * * *}(0.71,0.90)$ \\
\hline Lean Mass Index (kg/m²) & $0.75(0.53,1.06)$ & $0.69^{*}(0.49,0.98)$ & $1.10(0.79,1.53)$ & $0.96(0.69,1.33)$ & $0.69 *(0.48,0.98)$ \\
\hline Leanness Sport ${ }^{b}$ & $0.85(0.31,2.34)$ & $1.11(0.41,3.04)$ & $0.73(0.26,2.01)$ & $1.45(0.53,4.00)$ & $1.45(0.53,4.00)$ \\
\hline \multicolumn{6}{|l|}{ Sport Impact Type c } \\
\hline Ml vs. LI & $0.94(0.28,3.21)$ & $1.00(0.29,3.40)$ & $0.89(0.26,3.04)$ & $1.57(0.45,5.42)$ & $2.24(0.62,8.14)$ \\
\hline HI vs. LI & $1.17(0.24,5.62)$ & $0.86(0.18,4.13)$ & $3.33(0.60,18.54)$ & $0.88(0.18,4.34)$ & $1.71(0.34,8.68)$ \\
\hline
\end{tabular}

${ }^{a}$ Categorized as C+P-R: current and past regular menses; C/P-RIR: current or past irregular menses; C+P-IR: current and past irregular menses C+P-R is the reference category. b Leanness Sports included endurance, aesthetic, weight-class, and antigravitation sports; Non-leanness sports included technical, ball game, and power sports (Torstveit and Sundgot-Borgen, MSSE, 2005).

c Sport impact type included low impact, moderate impact, and high impact sports (Torstveit and Sundgot-Borgen, Br J Sports Med, 2005). Low impact is the reference category. " $p<0.05$ Wald statistic; * $p<0.01$ Wald statistic; ${ }^{* * *} p<0.001$ Wald statistic 
Table 5. Crude odds ratios and 95\% confidence intervals for low BMD, defined as Z-score <-1, at multiple sites.

\begin{tabular}{|c|c|c|c|}
\hline & $\begin{array}{l}\text { Low LS BMD } \\
\text { OR }(95 \% \mathrm{Cl})\end{array}$ & $\begin{array}{c}\text { Low FN BMD } \\
\text { OR }(95 \% \mathrm{Cl})\end{array}$ & $\begin{array}{c}\text { Low Hip BMD } \\
\text { OR }(95 \% \mathrm{Cl})\end{array}$ \\
\hline \multicolumn{4}{|l|}{$\begin{array}{l}\text { Cumulative Menstrual } \\
\text { Status }^{\text {a }}\end{array}$} \\
\hline$C+P-I R$ vs. $C+P-R$ & $6.79^{*}(1.45,31.89)$ & $0.38(0.07,2.03)$ & $1.03(0.18,5.73)$ \\
\hline C/P-RIR vs. C+P-R & $1.66(0.25,11.02)$ & $1.48(0.29,7.54)$ & $1.05(0.14,8.18)$ \\
\hline Age of Menarche (yrs) & $1.42^{*}(1.07,1.90)$ & $0.83(0.53,1.30)$ & $1.35(0.89,2.04)$ \\
\hline Body Mass (kg) & $0.89^{* *}(0.82,0.96)$ & $0.92(0.83,1.02)$ & $0.97(0.87,1.07)$ \\
\hline Height $(\mathrm{cm})$ & $0.96(0.90,1.03)$ & $\mathbf{0 . 8 9 *}(0.79,0.99)$ & $0.95(0.86,1.06)$ \\
\hline Body Mass Index $\left(\mathrm{kg} / \mathrm{m}^{2}\right)$ & $\mathbf{0 . 7 2 * *}(0.57,0.91)$ & $0.96(0.70,1.31)$ & $0.97(0.70,1.35)$ \\
\hline Lean Body Mass (kg) & $0.90(0.81,1.01)$ & $\mathbf{0 . 7 6 ^ { * * }}(0.63,0.92)$ & $0.93(0.80,1.09)$ \\
\hline Lean Mass Index $\left(\mathrm{kg} / \mathrm{m}^{2}\right)$ & $0.78(0.54,1.12)$ & $0.56^{*}(0.32,0.99)$ & $0.89(0.51,1.55)$ \\
\hline Leanness Sport ${ }^{b}$ & $1.72(0.52,5.65)$ & $1.06(0.21,5.39)$ & $2.22(0.26,18.83)$ \\
\hline \multicolumn{4}{|l|}{ Sport Impact Type c } \\
\hline Ml vs. LI & $2.02(0.41,10.01)$ & $0.99(0.11,8.99)$ & $0.99(0.11,8.99)$ \\
\hline HI vs. LI & $1.67(0.25,11.07)$ & $2.54(0.23,28.02)$ & $1.57(0.13,19.67)$ \\
\hline
\end{tabular}

a Categorized as C+P-R: current and past regular menses; C/P-RIR: current or past irregular menses; C+P-IR: current and past irregular menses C+P-R is the reference category. b Leanness Sports included endurance, aesthetic, weight-class, and antigravitation sports; Non-leanness sports included technical, ball game, and power sports (Torstveit and Sundgot-Borgen, MSSE, 2005).

c Sport impact type included low impact, moderate impact, and high impact sports (Torstveit and Sundgot-Borgen, Br J Sports Med, 2005). Low impact is the reference category. ${ }^{*} p<0.05$ Wald statistic; ${ }^{* *} p<0.01$ Wald statistic; ${ }^{* * *} p<0.001$ Wald statistic 